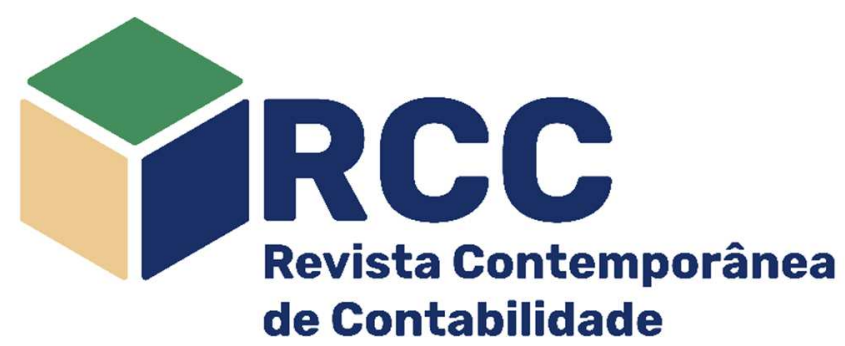

\title{
Pesquisas experimentais aplicadas à educação contábil: panorama atual e oportunidades no cenário brasileiro
}

\author{
Experimental research applied to accounting education: current panorama and future opportunities \\ in the Brazilian scenario
}

\begin{abstract}
Investigación experimental aplicada a la educación contable: panorama actual y oportunidades en el escenario brasileño
\end{abstract}

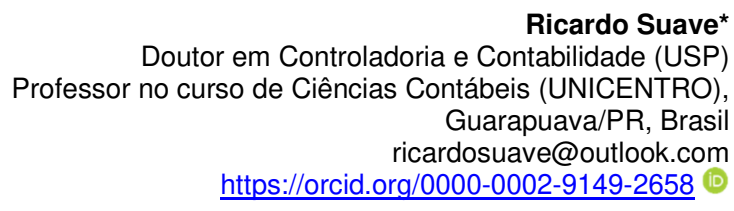

Ricardo Suave*

Doutor em Controladoria e Contabilidade (USP)

Guarapuava/PR, Brasil https://orcid.org/0000-0002-9149-2658 (B)
Stella Maris Lima Altoé Doutora em Contabilidade (UFPR) Professora no curso de Ciências Contábeis (UNICENTRO),

Guarapuava/PR, Brasil

stella.altoe@gmail.com https://orcid.org/0000-0001-9252-7835 (1)

Marcelo Marchine Ferreira Doutor em Educação (UFSCAR) Professor no Curso de Ciências Contábeis (UNESPAR), Campo Mourão/PR, Brasil mmarchine@gmail.com https://orcid.org/0000-0002-0102-7622

Endereço do contato principal para correspondência* Rua Padre Salvatore Renna, 875, Santa Cruz, CEP: 85015-430, Guarapuava/PR, Brasil

\begin{abstract}
Resumo
Artigos científicos que adotem o método experimental na área contábil, no Brasil, são pouco frequentes. No campo da educação contábil são menos frequentes ainda. Nesse sentido, o objetivo do estudo foi descrever, a partir de revisão narrativa de literatura especificamente selecionada, estudos nacionais e internacionais no campo da educação contábil que utilizaram método experimental e quase-experimental e, adicionalmente, apresentar oportunidades de pesquisas nesse campo com o uso do método. Metodologicamente o estudo tem caráter bibliográfico. Após procedimentos de levantamentos junto a revistas contábeis, obtiveram-se 7 artigos nacionais e 76 internacionais, cuja metodologia usada foi experimento ou quase experimento. Como resultados percebeu-se que os objetivos dos estudos, nacionais e internacionais, são semelhantes, com foco na verificação de efeitos de diferentes metodologias sobre o desempenho e satisfação dos estudantes. Entretanto, a principal diferença reside na quantidade, que por ser superior no contexto internacional, resulta em maior variedade de temas estudados. A principal contribuição do estudo é no sentido de demonstrar oportunidades do uso de experimentos para a promoção de melhorias em práticas de ensino, de aprendizagem, de formação de professores e em políticas institucionais.
\end{abstract}

Palavras-chave: Contabilidade; Educação; Experimentos

\begin{abstract}
Scientific studies that adopt the experimental method in the accounting area, in brazil, are uncommon. In the field of accounting education, they are even less frequent. In this sense, the aim of the study was to describe, based on a narrative review of the specifically selected literature, national and international studies in the field of accounting education using an experimental and quasi-experimental method and, additionally, to present research opportunities in this field with the use of the method. Methodologically, the study has a bibliographic character. After surveying procedures with accounting journals, 7 national and 76 international papers were obtained, whose methodology used was experiment or quasi-experiment. As a result, the objectives of the studies, national and international, are similar, with a focus on verifying the effects of different methodologies on student performance and satisfaction. However, the main difference lies in the number of studies, which was higher in the international context, and resulted in a wide array of topics studied. The main contribution of
\end{abstract}


the study is to demonstrate opportunities for using experiments to promote improvements in teaching, learning, professor training and institutional policies.

Keywords: Accounting; Education; Experiments

\section{Resumen}

Los artículos científicos que adoptan el método experimental en el área contable, en Brasil, son poco comunes. En el campo de la educación contable son incluso menos frecuentes. En este sentido, el objetivo del estudio fue describir, a partir de una revisión narrativa de literatura específicamente seleccionada, estudios nacionales e internacionales en el campo de la educación contable que utilizaron un método experimental y cuasiexperimental y, adicionalmente, presentar oportunidades de investigación. en este campo con el uso del método. Metodológicamente, el estudio tiene carácter bibliográfico. Luego de procedimientos de encuesta con revistas de contabilidad, se obtuvieron 7 artículos nacionales y 76 internacionales, cuya metodología utilizada fue un experimento. Como resultado, se notó que los objetivos de los estudios, nacionales e internacionales, son similares, con un enfoque en verificar los efectos de diferentes metodologías en el desempeño y satisfacción de los estudiantes. Sin embargo, la principal diferencia radica en la cantidad, que, al ser mayor en el contexto internacional, se traduce en una mayor variedad de temas estudiados. La principal contribución del estudio es demostrar oportunidades para el uso de experimentos para promover mejoras en la enseñanza, el aprendizaje, la formación docente y las políticas institucionales.

Palabras clave: Contabilidad; Educación; Experimentos

\section{Introdução}

O campo científico em contabilidade, de modo geral, tem crescido no Brasil. Tem havido também, como consequência, maior interesse pela pesquisa contábil e expansão da comunidade científica (Miranda, Santos, Nova \& Cornacchione Junior, 2013, Vendramin \& Araújo, 2016). A expansão do ensino superior brasileiro, a maior oferta de cursos de graduação de Ciências Contábeis e o crescimento, em anos recentes, do quantitativo de programas de pós-graduação stricto sensu na área contábil - principais vetores do desenvolvimento científico e de formação docente em contabilidade - são fatores que contribuem diretamente para o crescimento da comunidade e do interesse pelo campo (Silva, Ferreira, Leal \& Miranda, 2019).

Apesar da expansão e de seu desenvolvimento, a pesquisa contábil brasileira, de forma geral, tem trilhado o mesmo caminho de outros campos investigativos, caracterizando-se predominantemente pelo paradigma positivista e pela lógica produtivista (Costa \& Martins, 2016). O que acaba por gerar distorções críticas em termos de relevância e qualidade do conhecimento que está sendo gerado. Uma dessas distorções, apontada por Sangster, Forgaty, Stoner e Marriot (2015) e por Hartmann (2017), trata-se da existência considerável de distanciamento entre o conhecimento acadêmico, produzido pelas pesquisas e o conhecimento utilizável, capaz de ser adicionado ao repertório de quem tem interesse e possa utilizá-lo. Tal distorção resulta no que Hartmann (2017) denomina de estagnação acadêmica, isto é, a baixa interlocução que o conhecimento gerado pelas pesquisas tem com o exercício e a prática profissional contábil.

O desenvolvimento das pesquisas em educação contábil, apesar de também apresentar consistente evolução, aparenta ainda permanecer como um campo investigativo de menor ordem e atenção (Matos, Niyama, Fernandes \& Botelho, 2012; Miranda et al., 2013; Vendramin \& Araújo, 2016). Mesmo que os programas de pós-graduação sejam considerados o lócus para a formação de professores para o ensino, há evidencias que sugerem que tal papel não tem sido desempenhado suficientemente por eles ainda, cujo foco parece recair prioritariamente na formação do pesquisador (Vendramin \& Araújo, 2016; Laffin, \& Gomes, 2016). São poucos os programas que contemplam ações estruturadas em suas composições pedagógicas em termos de formação de professores para o ensino e de pesquisa sobre a educação em contabilidade (Vendramin \& Araújo, 2016; Laffin, \& Gomes, 2016), o que provavelmente implica em pouco desenvolvimento de investigações consistentes e regulares sobre a interrelação entre educação e contabilidade.

Nesse sentido, é preciso que o gap entre o conhecimento gerado pela produção científica e a prática educativa em contabilidade diminua. E que a prática educativa se alimente do conhecimento gerado de modo a promover efetivas mudanças em processos de ensino e de aprendizagem contábil. Todavia, é preciso que, dentre outras coisas, o campo investigativo em contabilidade explore e diversifique a forma de conduzir os estudos, uma vez que está marcado pela lógica reprodutivista e por escolhas que tendem a reforçar a manutenção do habitus em que foram formados dos pesquisadores do campo (Costa \& Martins, 2016). Uma das maneiras de alterar esse cenário guarda relação com mudanças no aspecto metodológico das pesquisas. Métodos de pesquisa pouco usuais em contabilidade - e que potencialmente podem contribuir com a retroalimentação conhecimento-prática - precisam de iniciativa e espaço para serem desenvolvidos e aplicados. Tanto no campo dos métodos qualitativos quanto quantitativos. E este estudo, trata de um em específico: o método experimental.

Experimentos estão relacionados ao desenvolvimento da ciência e do pensamento científico. $\mathrm{Na}$ literatura, seu conceito apresenta variação interpretativa. No contexto do ensino de ciências, "experimentar [...] é submeter à experiência; é por à prova; é ensaiar; é conhecer ou avaliar pela experiência" (Borges \& 
Moraes, 1998, p. 30). Já no campo da pesquisa científica, experimento é um método de natureza intervencionista e com procedimentos próprios (Teixeira \& Megid Neto, 2017). Consiste na realização de uma ação para observação de suas consequências na busca por "[...] construir novos conhecimentos, desconhecidos para a própria ciência" (Lima \& Teixeira, 2005, p. 2). É nesse sentido que os experimentos são abordados no presente estudo.

Um estudo experimental consiste na modificação deliberada e controlada das condições determinantes de um dado fenômeno e a consequente observação e interpretação das modificações que nele ocorreram. E a partir de tais observações e interpretações, desvelar as causas do fenômeno indicando qual ou quais variáveis produziram modificações sobre outras variáveis (Triviños, 1987). O controle das condições pelo pesquisador ocorre quando uma ou mais variáveis independentes - causas antecedentes - são manipuladas intencionalmente com objetivo de analisar suas consequências sobre uma ou mais variáveis dependentes - efeitos consequentes (Sampieri, Collado \& Lucio, 2013). Tal desenho permite a inferência de relação causal, que é importante para se constatar que as diferenças observadas serão resultantes exclusivamente das manipulações realizadas. Se o experimento for adequadamente desenhado, com cuidado na validade do construto e nas validades interna e externa, a relação causal poderá ser inferida, explicando o fenômeno em estudo.

Em se tratando de pesquisas no campo da contabilidade o uso de experimentos, de forma geral, é algo recente (Aguiar, 2017, 2018; Hesford, Lee, Van der Stede e Young, 2007). Tal uso no Brasil, além de recente, também é escasso (Frezatti, Aguiar, Wanderley \& Malagueño, 2015; Homero Jr., 2016, Aguiar, 2017, 2018). O estudo de Aguiar (2018), por exemplo, identificou que de um total de 99 estudos sobre contabilidade gerencial publicados em periódicos no Brasil, apenas 3 utilizaram o método experimental. No Journal of Accounting Education, que apresenta revisões de literatura a partir dos principais periódicos de educação contábil, verificou-se que de 2010 a 2018 apenas 2,3\% dos estudos empíricos analisados utilizaram experimentos como método (Apostolou, Dorminey, Hassell, \& Watson, 2013; Apostolou, Dorminey, Hassell, \& Rebele, 2015, 2016, 2017, 2018; Apostolou, Dorminey, Hassell, \& Hickey, 2019).

Entretanto, a literatura aponta potencialidades que possibilitariam importantes contribuições para o avanço dos conhecimentos e das práticas profissionais em diversos segmentos como contabilidade financeira, gerencial e auditoria, por exemplo (Aguiar, 2017). A eles pode ser adicionado o ensino de contabilidade. No campo do ensino seu uso pode ser útil, por exemplo, com foco no processo de ensino e aprendizagem, testando os efeitos de determinadas metodologias sobre o aprendizado dos estudantes (Street, 1995; Abeysekera, 2015; Sithole, 2017). Ou mesmo verificando a resposta comportamental do estudante a determinados estímulos e estabelecer a relação dos efeitos sobre o desempenho, sobre o engajamento nos estudos, sobre a motivação com o curso. Outra possibilidade seria em questões relativas à docência, verificando se há relação entre políticas institucionais diversas (salariais, de benefícios, promoções e progressões de carreira, de qualificação, de formação docente, por exemplo) e o desempenho docente em aula, em pesquisa ou em relação ao engajamento do docente com a instituição e/ou curso. Outros focos também poderiam ser explorados por estudos experimentais no ensino de contabilidade em áreas como currículo, tecnologias aplicadas ao ensino ou práticas educativas, por exemplo.

No sentido do que foi exposto, conhecer mais especificamente o que tem sido investigado nas pesquisas sobre educação contábil que utilizaram o método experimental induziu a inquietação deste estudo. De tal modo, o objetivo foi descrever, a partir de revisão narrativa de literatura especificamente selecionada, estudos nacionais e internacionais no campo da educação contábil que utilizaram método experimental e quase-experimental. Adicionalmente, apresentar oportunidades de pesquisas nesse campo com o uso do método. A inclusão dos quase-experimentos no escopo do estudo se deve ao fato de possuírem objetivos e atributos estruturais semelhantes aos experimentos (Shadish, Cook \& Campbell, 2002).

De forma geral, a pouca evidência de utilização do método experimental no campo da investigação sobre a educação contábil no Brasil e fora dele pressupõe, portanto, um horizonte investigativo potencial a ser explorado (Aguiar, 2017, 2018; Apostolou et al., 2013, 2015, 2016, 2017, 2018, 2019). Nesse sentido, este estudo preenche uma lacuna ao ter realizado uma investigação revisional em parcela significativa da literatura contábil nacional e internacional sobre o uso do método em pesquisas educacionais em contabilidade e apontado oportunidades de pesquisas com tal método que podem potencialmente promover modificações nas práticas de ensino, de aprendizagem, de formação de professores e em políticas institucionais. Cabe ressaltar, entretanto, que este estudo não pretendeu, por óbvio, esgotar as inúmeras e múltiplas possibilidades de pesquisas existentes.

A principal contribuição deste estudo, portanto, está no conhecimento que gerou sobre produções científicas que usaram o método experimental e quase-experimental em investigações relacionadas à educação contábil. Proporcionou também compreensão das áreas temáticas abordadas nas investigações que foram divulgadas nos principais periódicos nacionais sobre contabilidade e nos internacionais sobre educação contábil. Adicionalmente, o conhecimento gerado pode ter valor potencial para pesquisadores em educação contábil que vão desenvolver ou que estão desenvolvendo pesquisa sobre o tema, pois permitirá que identifiquem temáticas e direcionamentos ainda pouco explorados com o uso do método experimental. Assim, este estudo pretende explorar e, ao mesmo tempo, problematizar sobre o uso do método em pesquisas 
sobre educação contábil, levantando desafios e possibilidades que podem ser encaminhadas em pesquisas futuras.

\section{Uso de Experimentos em Pesquisas de Educação}

Nas últimas duas décadas muito se tem avançado na pesquisa em educação com o uso de métodos experimentais, pois a partir desta metodologia, com uso de testes que verificam relações de causa e efeito, pode-se inferir sobre o que funciona ou não em práticas educacionais (Raudenbush \& Schwartz, 2020; Whitehurst, 2012). A maior utilização de experimentos foi uma mudança de rumo em relação a metodologias de pesquisa anteriores, amplamente baseadas em estudos de abordagem não experimental, em que se observava a falta de sucesso na identificação de efeitos causais confiáveis (Pituch, Murphy \& Tate, 2010).

A evolução observada se deve, principalmente, pelo uso de estudos randomizados, ou seja, a aleatoriedade na designação dos participantes aos grupos de tratamento e controle. Assim, com facilidade de interpretação de resultados, há a garantia de que as diferenças observadas entre esses grupos são em decorrência do tratamento realizado, o que permite atestar relação de causa e efeito (Whitehurst, 2012). Nesse sentido, observa-se que estudos com esta abordagem fornecem base científica para a formulação de diretrizes de políticas, métodos e práticas educacionais (Pituch et al., 2010).

Em particular, na pesquisa em educação contábil, argumenta-se acerca de uma estagnação, tendo em vista que artigos empíricos geralmente adotam levantamentos, com poucos estudos que utilizam de abordagens experimentais ou quase experimentais (Rebele \& Pierre, 2015). Pondera-se, entretanto, que a questão de pesquisa norteia o método a ser usado. Por exemplo, uma pesquisa com o intuito de verificar a satisfação dos estudantes sobre determinado assunto não necessitaria de experimento, por outro lado, tal abordagem é mais adequada para a análise do desempenho dos estudantes após a adoção de nova metodologia. Ou seja, os experimentos são mais aplicáveis para demonstrar o que funciona (ex., metodologias de ensino, de avaliação, entre outros) (Whitehurst, 2012). A partir desse contexto, fica claro que a inferência causal é o principal benefício dos experimentos.

Recomendações para maior uso de experimentos em detrimento de levantamentos não são recentes (Benke \& Street, 1992; Street, 1995), inobstante estudos revisionais da área não demonstram esse uso como tendência. Para ilustrar o contexto internacional, apresenta-se a seguir a Tabela 1, em que estudos realizados no período de 2010 a 2019 são elencados. Salienta-se que desde 1986 são publicados estudos revisionais dessa série, tendo início com Rebele \& Tiller (1986). A partir do segundo estudo, realizado em 1991 por Rebele, Stout \& Hassell, (1991), as pesquisas passaram a ser publicadas no Journal of Accounting Education, e somente a partir de 2013 verifica-se a direta evidenciação da quantidade de artigos por tipo de metodologia, com o estudo de Apostolou, Dorminey, Hassell, e Watson (2013).

Tabela 1:

Identificação do uso de experimentos em estudos revisionais

\begin{tabular}{l|l|c|c|c}
\hline Período & Estudo & Total & $\begin{array}{l}\text { No de } \\
\text { experimentos }\end{array}$ & $\begin{array}{l}\text { № de quase } \\
\text { experimentos }\end{array}$ \\
\hline $2010-2012$ & Apostolou, Dorminey, Hassell, e Watson (2013) & 291 & $2(0,7 \%)$ & $23(7,9 \%)$ \\
\hline $2013-2014$ & Apostolou, Dorminey, Hassell, e Rebele (2015) & 256 & $1(0,4 \%)$ & $12(4,7 \%)$ \\
\hline 2015 & Apostolou, Dorminey, Hassell, e Rebele (2016) & 97 & $1(1 \%)$ & $7(7 \%)$ \\
\hline 2016 & Apostolou, Dorminey, Hassell, e Rebele (2017) & 108 & - & $7(6,5 \%)$ \\
\hline 2017 & Apostolou, Dorminey, Hassell, e Rebele (2018) & 103 & $1(1 \%)$ & $3(3 \%)$ \\
\hline 2018 & Apostolou, Dorminey, Hassell, e Hickey (2019) & 101 & $3(3 \%)$ & $1(1 \%)$ \\
\hline 2019 & Apostolou, Dorminey, and Hassell (2020) & 81 & - & $5(6,2 \%)$ \\
\hline
\end{tabular}

Fonte: os autores (2021).

A partir da Tabela 1 é possível observar que, para os diferentes períodos analisados, não se verifica tendência de aumento ou redução significativos da quantidade de pesquisas, tampouco de variações da representatividade de experimentos e quase experimentos em relação a esse total. Enquanto tais metodologias foram adotadas por 8 e 58 estudos no período, respectivamente, o levantamento como estratégia de coleta de dados foi adotado por 236 estudos nesse período. Nesse sentido, é notável que o uso de experimentos e quase experimentos continua pouco representativo, ou seja, ainda em linha com o argumento de estagnação da pesquisa de educação contábil (Rebele \& Pierre, 2015).

A maioria dos estudos analisados que utilizam abordagens não experimentais proporcionam resultados que capturam associações, em vez de causa e efeito (Apostolou et al. 2019). Segundo os autores, a identificação de relações de causa e efeito podem ser realizadas por meio de abordagens experimentais aleatórias e controladas, pois possibilitam o isolamento de construtos. Métodos experimentais e quase experimentais, além de dados de desempenho dos estudantes, são formas de coleta de dados consideradas como mais rigorosas, mas que seu uso vem diminuindo (Apostolou et al., 2018).

Rebele e Pierre (2015) elencam alguns desafios relacionados a aplicação de estudos experimentais no campo educacional. O primeiro diz respeito à aprovação em comitê de ética, pois geralmente há a expectativa de que o grupo de tratamento poderá se beneficiar de algo que se pretende estudar, e o grupo 
de controle não. Assim, desempenho (notas) e atitudes dos estudantes, em relação à uma disciplina, podem ser afetados quando participam do estudo. Em segundo lugar, as taxas de desistência de uma disciplina podem ser diferentes entre os grupos de controle e tratamento, e há a possibilidade de o tratamento afetar a decisão de desistência.

Outro desafio inerente ao uso dos experimentos, e de qualquer tipo de pesquisa, diz respeito à validade do construto e às validades interna e externa. A validade do construto descreve o quanto que abstrações podem ser operacionalizadas, seja em termos de confiabilidade da mensuração até a habilidade de as medidas captarem a essência da abstração (Smith, 2003). A validade interna se refere à inferência de causa e efeito de $A$ para $B$ na forma como tais variáveis foram mensuradas, o que requer que o pesquisador ateste que A precede B no tempo (Shadish et al., 2002). Por fim, a validade externa tem relação com a capacidade de generalização dos resultados (Smith, 2003).

Aguiar (2017) explicita três tipos de experimentos (natural, de campo e de laboratório) a partir de pesquisas da contabilidade, bem como as vantagens e desvantagens de cada um relacionadas às validades interna e externa. Em um experimento natural o pesquisador não manipula variáveis independentes, e, em relação aos demais tipos de experimento, possui maior validade externa e menor validade interna. Aplicado à educação em contabilidade, um fato exógeno ao controle do pesquisador pode ser alguma mudança curricular, assim, pode-se estudar se há diferença em alguma variável dependente (desempenho dos estudantes, colocação no mercado) comparando-se o antes e depois da mudança. Nesse caso, o problema da validade interna se refere à dificuldade de controlar o efeito de variáveis alheias ao desenho do estudo (Aguiar, 2017).

O experimento de campo, por sua vez, acontece quando uma intervenção é feita com alguns alunos e os demais são o grupo de controle. Essa abordagem possui maior validade externa do que experimentos de laboratório, especialmente pela aplicação direta com alunos, mas menor validade interna do que experimentos de laboratório (Aguiar, 2017). A implementação de nova forma de avaliação ou metodologia de ensino, aleatória entre um grupo de alunos de contabilidade de uma universidade, são exemplos de experimentos de campo. Por fim, em relação às abordagens anteriores, o experimento de laboratório possui menor validade externa e maior validade interna, pelo fato de haver maior uso de abstração e maior controle do pesquisador, respectivamente (Aguiar, 2017). Como exemplos de experimentos de laboratório na educação, menciona-se a aplicação de um teste hipotético com diferentes formas de questões (abertas ou fechadas) ou diferentes arranjos de estudantes (individual ou grupos), para verificação do efeito no desempenho.

Considerando os desafios e cuidados a serem tomados com o uso de experimentos, é válido empreender a iniciativa de aplicar tal metodologia na pesquisa em educação contábil para que assim os benefícios desse método possam também ser aproveitados e aprimorados. Na sequência, apresentam-se os principais aspectos do delineamento metodológico do estudo.

\section{Método}

A pesquisa teve orientação qualitativa, de caráter revisional e interpretativa. $O$ tipo de revisão de literatura adotado localiza-se entre a narrativa e a sistemática. Isso porque parte do delineamento adotado (especificamente a opção pelo conjunto específico dos periódicos investigados ao invés de bases de indexação de periódicos) foi estabelecido pelo julgamento dos autores deste estudo e parte foi estabelecido em protocolo de pesquisa. $O$ foco foi descrever as pesquisas realizadas com uso da abordagem experimental e quase-experimental para, adicionalmente, apontar direções para investigações possíveis e consideradas como potenciais com uso de experimentos no campo da educação contábil no Brasil.

O corpus de literatura investigado foi composto por artigos publicados em periódicos científicos nacionais e internacionais no campo contábil. A opção, delineada no estudo, foi a de conhecer o que vem sendo publicado em periódicos contábeis representativos em termos de publicações sobre educação contábil. Internacionalmente existem revistas específicas, especializadas em educação contábil. São periódicos consolidados e, por isso, considerados representativos no tocante à divulgação de pesquisas educacionais e ao alcance que possuem dentro do campo científico e profissional contábil. No Brasil, por outro lado, não há periódicos especializados destinados especificamente ao assunto. As publicações sobre educação contábil encontram espaço em quase todos, que também publicam artigos nas diversas áreas do conhecimento contábil. Devido a isso, a opção do estudo foi por incluir o conjunto dos periódicos de contabilidade brasileiros, o que permite afirmar que são, do mesmo modo, representativos nos cenários da pesquisa e profissional nacional. Evidentemente que o caminho escolhido implica em limitações, onde a principal reside no fato de que pesquisas sobre educação contábil que utilizaram o método experimental podem ter sido publicadas em periódicos que se encontram fora do escopo contábil.

Assim, com relação aos artigos nacionais, o corpus foi composto de 40 periódicos selecionados por constarem na classificação Qualis-Periódicos da área de Administração Pública e de Empresas, Ciências Contábeis e Turismo realizado pela CAPES para o quadriênio 2013-2016 (disponível em: https://tinyurl.com/oedf4xj). A busca dos artigos nos periódicos brasileiros ocorreu por acesso ao endereço eletrônico específico de cada um deles. Foram utilizados como descritores os termos 'experimento' e 
'experiment', com o critério de que poderiam aparecer no título, resumo ou palavras-chave. O recorte temporal foi amplo e diversificado, cobrindo o período de disponibilidade online das publicações de cada um dos periódicos. Após análise preliminar seletiva do material recuperado com a busca realizada, foram incluídos no corpus sete artigos. Os critérios para inclusão dos artigos foram dois: que tivessem delineamento metodológico como experimento ou quase-experimento e que os estudos investigassem assuntos/temas sobre educação contábil.

Com relação aos artigos internacionais, foram selecionados a partir do mesmo conjunto de periódicos sobre educação contábil utilizado nos estudos de Apostolou et al. (2013, 2015, 2016, 2017, 2018). Tais estudos são parte de uma série de pesquisas revisionais publicados no Journal of Accounting Education e centram suas análises em seis periódicos específicos sobre o campo da educação em contabilidade, sendo eles: Journal of Accounting Education, Accounting Education, Advances in Accounting Education: Teaching and Curriculum Innovations, Global Perspectives on Accounting Education, Issues in Accounting Education e The Accounting Educators' Journal. As publicações da autora e colaboradores mapeiam, dentre outros tópicos, as diversas áreas e assuntos em que são desenvolvidas as pesquisas publicadas nas revistas que, por sua vez, são tomadas como referências consistentes em termos de divulgação de conhecimentos sobre educação contábil.

A busca dos artigos nos periódicos internacionais ocorreu de maneira similar à descrita para os periódicos nacionais. Foi acessado o endereço eletrônico específico de cada um deles e utilizado como descritor o termo 'experiment', com o critério de que poderia aparecer no título, resumo ou palavras-chave. Após análise seletiva do material, foram incluídos no corpus 76 artigos que se encaixaram como experimentos e cuja investigação foi sobre educação contábil.

A análise do corpus adotou orientação que se aproxima da descrição interpretativa. Abordagens interpretativas, em pesquisas qualitativas, preocupam-se em compreender os significados do fenômeno investigado, sem predeterminações a priori (Pozzebon \& Petrini, 2013). Já a descrição interpretativa, aqui ressignificada e apropriada para um estudo de natureza revisional, assume perspectiva analítica indutiva, projetada com a finalidade de criar maneiras de compreender o conjunto das publicações científicas de uma temática específica que utilizaram um método determinado. E tal compreensão gerada pela interpretação dos investigadores tem potencial de produzir implicações para o contexto investigado e, portanto, para a prática investigativa do próprio campo (Teodoro, Rebouças, Thorne, Souza, Brito \& Alencar, 2018). Na descrição interpretativa o papel do pesquisador delineia-se pela necessidade de sua realidade para geração de novos conhecimentos, cabendo a ele combinar a compreensão do que já é conhecido com novas possibilidades na estruturação do conhecimento (Teodoro et al., 2018).

Nesse sentido, a ideia subjacente à opção analítica adotada foi a de explorar como as pesquisas experimentais em educação contábil têm sido. O caminho analítico considerou a descrição (não estatística) dos estudos e buscou organizá-los e sintetizá-los em áreas temáticas. Tal organização e sintetização ocorreu à posteriori, sendo constituída a partir dos próprios dados (artigos analisados). Posteriormente, e a partir dos estudos investigados, buscou-se organizar os encaminhamentos para pesquisas futuras, adicionando contribuições não contempladas pelo corpus analisado.

\section{Resultados e Discussão}

\subsection{Experimentos nas pesquisas contábeis brasileiras sobre educação}

Os estudos sobre educação contábil com uso da abordagem experimental (e quase-experimental) em periódicos contábeis brasileiros são escassos. No levantamento realizado foram identificados sete que puderam ser objetivamente associados ao uso da abordagem. No processo de análise, foram agrupados em quatro áreas temáticas, conforme demonstra a figura 1. Faz-se importante mencionar que um determinado estudo pôde ser agrupado em mais de uma área devido ao seu escopo estabelecido, como é o caso, por exemplo, do estudo de Passos, Cornacchione Júnior, Gaio e Brito (2016), incluído na área Comportamento e Características dos Estudantes e Ensino em Disciplinas Específicas.

Dentre os que avaliaram uma técnica ou uma estratégia didática específica, três estudos concentramse na autoria de Passos, Cornacchione Júnior, Gaio e Mori (2015), Passos, Cornacchione Júnior, Gaio e Brito (2016) e Passos Cornacchione Júnior, Gaio, Brito e Mori (2016). Em um quase-experimento, Passos et. al. (2015) buscaram conhecer, analisar e avaliar a efetividade em ensinar o modelo de Richard Paul (1995) de raciocínio crítico em alunos de graduação no ensino presencial em Ciências Contábeis da FEA-USP, no desenvolvimento de habilidades para pensar criticamente sobre contabilidade. O estudo, em seus resultados, evidenciou que os acadêmicos da turma de tratamento, com relação ao seu raciocínio crítico, não foram melhores que os acadêmicos da turma de controle. Logo, o modelo de Richard Paul não apresentou efeito significativo.

Passos, Cornacchione Júnior, Gaio e Brito (2016), em outro estudo de quase-experimento, avaliaram a aplicação do modelo de Richard Paul no ambiente virtual Moodle, utilizando o EWCTET. O estudo foi realizado com alunos que cursavam a disciplina de Orçamento Empresarial e Controladoria, do curso de Administração em uma Instituição de Ensino Superior (IES) do interior do Estado de São Paulo. Os resultados 
apontaram que o modelo de Richard Paul não teve efeito significativo para as habilidades de raciocínio crítico quando utilizado o ambiente virtual Moodle.

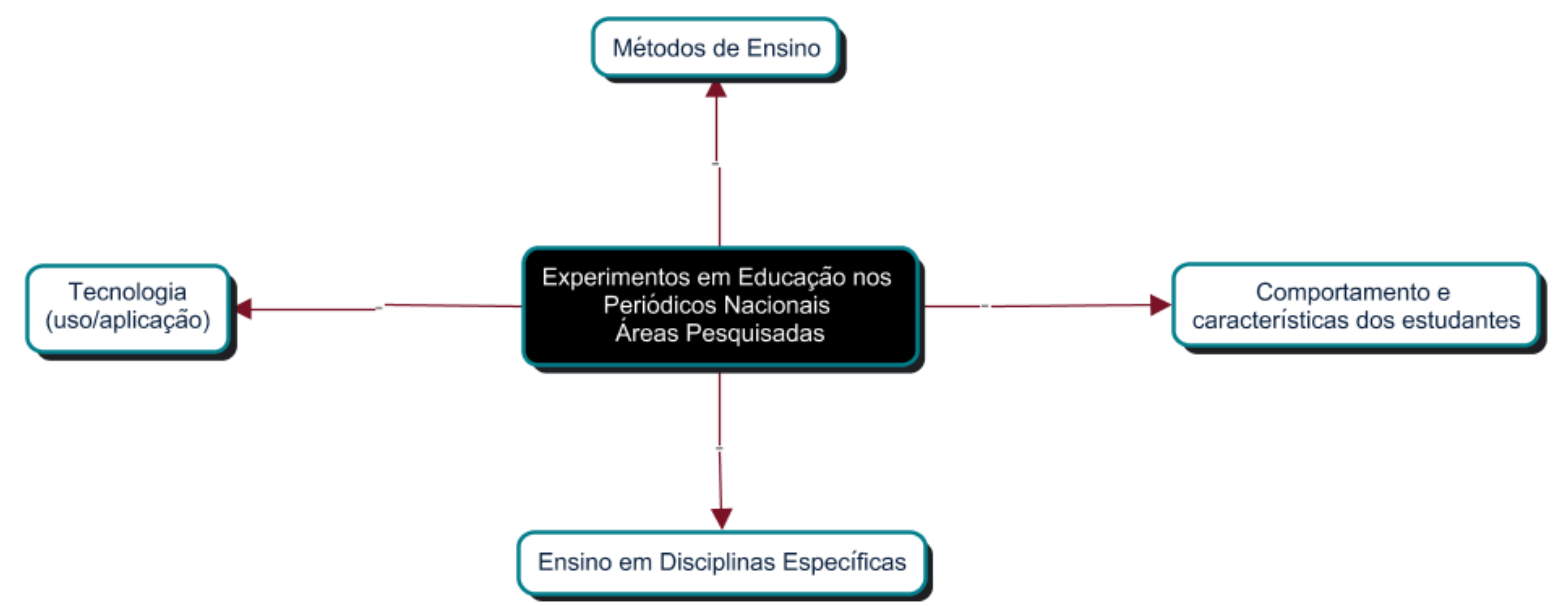

Figura 1: Áreas abordadas nos estudos experimentais e quase-experimentais nacionais Fonte: Elaborado pelos autores (2020).

Passos, Cornacchione Júnior, Gaio, Brito e Mori (2016) avaliaram a aplicação de uma simulação de Mercado de Capitais para o desenvolvimento de habilidades de raciocínio crítico, a partir do EWCTET, em alunos da área de negócios, tendo como principal inovação a inserção da variável Jogos de Empresas. O estudo foi realizado na disciplina de Mercado de Capitais em uma IES do interior do Estado de SP. Os resultados evidenciam que a simulação de Mercado de Capitais não obteve efeito significativo no desenvolvimento de habilidades de raciocínio crítico na turma de tratamento.

Quintana e Afonso (2018) verificaram o reflexo do uso da tecnologia no desempenho dos estudantes na disciplina de Contabilidade Introdutória de uma IES Federal. A partir de um experimento, as turmas foram divididas em grupos de tratamento e controle, com posterior inversão dos grupos para identificar o reflexo do uso de chat e fórum de discussão no processo de aprendizagem. Ressalta-se a importância da designação dos participantes em grupos de tratamento e controle como característica fundamental dos experimentos (Apostolou et al., 2018). No início de cada bimestre foi aplicada uma avaliação para aferir o nível de conhecimento prévio dos estudantes acerca do conteúdo. Os resultados do estudo apontam que a utilização de tecnologia, especificamente o chat e fóruns, contribui para o aumento do desempenho acadêmico.

Santos (2003) também utilizou a variável Jogos de Empresas em seu experimento. Investigou-se a aplicação dos Jogos de Empresas no ensino e aprendizagem em Contabilidade, destacando aspectos como: i) as abordagens teóricas dos processos de ensino e aprendizagem; ii) Jogos de Empresas e suas vantagens no ensino e aprendizagem; iii) Jogos de Empresas e a aprendizagem de adultos; iv) Jogos de Empresas e as abordagens de ensino e aprendizagem; v) Teoria dos Jogos e vi) Jogos de Empresas e a contabilidade. Os resultados encontrados demonstram que a estratégia de ensino denominada de Jogos de Empresas deve ser aplicada na aprendizagem de adultos e na educação centrada no discente, a partir do enfoque construtivista que é direcionado aos trabalhos em equipes. Além disso, constatou-se que nesse processo os participantes atuaram de forma ativa estimulando, assim, o ensino e a aprendizagem.

Pereira e Silva (2018) verificaram as contribuições que a aprendizagem cooperativa pode proporcionar para o desempenho acadêmico e para a habilidade de comunicação dos acadêmicos de Ciências Contábeis. Foi realizado um experimento com 34 acadêmicos da disciplina de Contabilidade Fiscal de uma IES pública, constituído de duas variáveis independentes, aprendizagem cooperativa em aula (aprendizagem Jigsaw) e aula expositiva tradicional, que mapearam o método de ensino. Já o nível de conhecimento foi fundamentado na Taxonomia de Bloom e caracterizou-se como variável dependente. Adicionalmente, os autores utilizaram a técnica Cloze, análise de variância e o teste de Tukey. Os achados mostram que a aprendizagem cooperativa contribui para a melhoria da habilidade de comunicação escrita, por outro lado, não apresenta diferença significativa para o desempenho acadêmico.

Carvalho Júnior, Rocha e Bruni (2010) verificaram o impacto do aprendizado formal de controladoria na minimização dos vieses cognitivos em decisões gerenciais, provocadas pelo efeito framing. Para tanto, construíram cenários referentes a custo de oportunidade, Sunk Costs, custo de reposição e teoria das restrições. Tais perspectivas, segundo os autores, podem apresentar vieses e relacionam-se ao aprendizado formal de controladoria. Além disso, analisou-se o efeito de variáveis intervenientes, definidas como desempenho acadêmico, nível percebido de conhecimento e estágio no curso, na diminuição do efeito framing. A amostra do estudo constituiu-se de estudantes dos estágios iniciais e finais dos cursos de Ciências Contábeis e Direito da Universidade Federal da Bahia (UFBA), o que resultou em uma amostra de 155 alunos. Os achados indicam que o efeito framing pode ser identificado em situações quando apresentam-se conceitos 
de custos irrecuperáveis e custo de reposição, sendo que para o custo de reposição a inserção do viés resultou em efeito framing na direção oposta ao pretendido.

Em síntese, no campo da educação em contabilidade no Brasil não tem se mostrado frequente a publicação de estudos que utilizem experimentos ou quase-experimentos como abordagem metodológica nos periódicos de contabilidade. Nos estudos encontrados há concentração de investigação em dois caminhos: os que avaliaram uma técnica ou uma estratégia didática específica e os que investigaram a relação entre o ensino e aprendizagem em situações específicas. Contudo, conforme demonstra a Figura 1, os estudos apontam para pouca diversidade de áreas. O que demonstra, ao mesmo tempo, um vazio a ser preenchido em relação ao uso de estudos experimentais no campo da educação contábil e uma oportunidade de explorar os experimentos e os quase-experimentos em uma ampla variedade de focos dentro da área educacional (Rebele \& Pierre, 2015).

Os dados analisados não permitem inferir sobre o desenvolvimento das pesquisas em educação contábil utilizando o método. Todavia, desperta a atenção o fato de que no conjunto dos periódicos contábeis brasileiros - principal canal de divulgação científica para a comunidade de pesquisa em contabilidade - não há frequência nem regularidade de estudos experimentais em educação ou em outras áreas (Aguiar, 2017). Tal constatação aponta também para um vasto campo de possibilidades a ser explorado no contexto brasileiro, tanto em termos de publicações quanto, possivelmente, de desenvolvimento de investigações que adotem o método.

\subsection{Experimentos nas pesquisas contábeis internacionais sobre educação}

As publicações de pesquisas que utilizam experimentos como método nas revistas contábeis sobre educação contábil internacionais (as selecionadas para o estudo) são frequentes e cobrem temáticas variadas e com enfoques diversos. A Figura 2 representa as temáticas dos estudos dentro do campo da educação contábil.

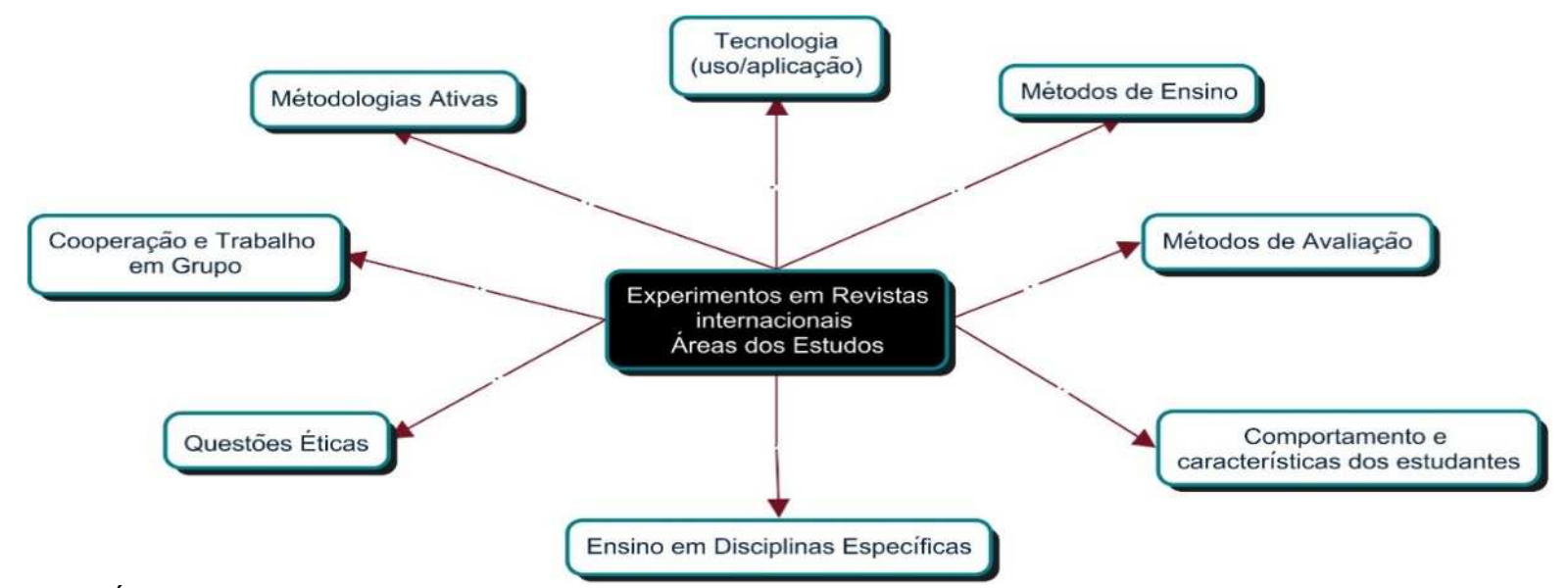

Figura 2: Áreas abordadas nos estudos experimentais e quase-experimentais internacionais Fonte: Elaborado pelos autores (2020).

Faz-se importante destacar que além de frequentes, as primeiras publicações levantadas datam de meados da década de 1980. Em comparação com a primeira publicação em periódicos nacionais, representa cerca de uma década e meia antes. Há também diversidade de autores. Nos tópicos a seguir os estudos são descritos em suas características, abordagens e resultados.

\subsubsection{Uso de tecnologias}

Artigos que estudam o uso de tecnologias no ensino em contabilidade evidenciam a evolução dos diferentes tipos de tecnologia, nesse sentido, percebe-se que o advento de novas tecnologias é estudado no contexto da educação contábil. Apesar de poderem ser classificados como métodos de ensino, decidiu-se por sua classificação em separado para evidenciar tal situação. Estudos contemporâneos ao início do uso de computadores tinham como curiosidade a investigação de seu uso e possíveis reflexos. Por exemplo, Alkafaji e Schroeder (1986) verificaram diferenças na realização de exercícios com computadores ou manualmente, em que se constatou que não havia diferenças significativas no desempenho, mas a velocidade na realização dos exercícios era maior para estudantes com computadores.

Enquanto estudos mais antigos reportam resultados referentes ao uso de novas tecnologias para a realização de tarefas, como é o caso dos estudos que verificaram o uso de computadores e planilhas próximo do seu surgimento (Marriott, 1992; Marriott \& Mellett, 1994; Mclnnes, Pyper, Van Der Meer \& Wilson 1995), estudos posteriores analisam o uso de tecnologias que se popularizaram para apresentação de conteúdo. Especificamente no uso do PowerPoint, os aspectos positivos são de que os estudantes melhoraram sua 
atitude em relação ao professor que usa tal mídia e o consideram mais eficiente e eficaz quando fornece as anotações; mas efeitos do uso da mídia na memória e do fornecimento das anotações no desempenho em provas não foram confirmados (Nouri \& Shahid, 2005; 2008).

\subsubsection{Métodos de ensino}

Nesse tópico são apresentadas diferentes formas adotadas por professores para o processo de ensino-aprendizagem. Geralmente, são formas mais inovadoras comparadas àquelas tidas como tradicionais. Um compêndio, não exaustivo das pesquisas resultantes do levantamento, é apresentado na Tabela 2. A coluna 'tratamento' se refere à técnica ou prática adotada, enquanto a coluna 'objetivo' se refere aos efeitos que se pretendeu analisar.

Tabela 2:

Estudos experimentais com métodos de ensino

\begin{tabular}{|c|c|c|c|}
\hline Estudo & Tratamento & Objetivo & Resultados \\
\hline $\begin{array}{l}\text { Anderson e } \\
\text { Boynton } \\
(1992)\end{array}$ & $\begin{array}{l}\text { Omissão de material } \\
\text { redundante incluído em } \\
\text { disciplina intermediária. }\end{array}$ & $\begin{array}{l}\text { Verificar o efeito sobre } \\
\text { o desempenho dos } \\
\text { estudantes. }\end{array}$ & $\begin{array}{l}\text { As evidências são de o tratamento não } \\
\text { causa efeito negativo no desempenho. } \\
\text { Tempo extra para conteúdos novos ou } \\
\text { mais difíceis. }\end{array}$ \\
\hline $\begin{array}{l}\text { Boritz, } \\
\text { Borthick e } \\
\text { Presslee } \\
\text { (2012) }\end{array}$ & $\begin{array}{l}\text { Uso de representação } \\
\text { diagramática, em detrimento } \\
\text { da textual, para uma tarefa de } \\
\text { avaliação de risco e controle. }\end{array}$ & $\begin{array}{l}\text { Verificar o } \\
\text { desempenho dos } \\
\text { estudantes na tarefa. } \\
\text { Examinar se o } \\
\text { desempenho } \\
\text { acadêmico dos alunos } \\
\text { e percepção de } \\
\text { habilidade afetam o } \\
\text { desempenho por tipo } \\
\text { de representação. }\end{array}$ & $\begin{array}{l}\text { Com relação à acurácia, não houve } \\
\text { diferença entre os métodos. Mas os } \\
\text { estudantes com representação textual } \\
\text { foram mais eficientes e tiveram melhor } \\
\text { desempenho. O desempenho acadêmico } \\
\text { não tem efeito e a habilidade percebida } \\
\text { reduz o desempenho. }\end{array}$ \\
\hline Brink (2013) & $\begin{array}{l}\text { Comparação entre seções da } \\
\text { disciplina sem questões, } \\
\text { questões apenas após, e } \\
\text { questões antes e depois. }\end{array}$ & $\begin{array}{l}\text { Verificar o } \\
\text { desempenho dos } \\
\text { estudantes em relação } \\
\text { à aplicação das } \\
\text { questões on-line. }\end{array}$ & $\begin{array}{l}\text { O uso de questões antes e depois dos } \\
\text { conteúdos melhoram a preparação dos } \\
\text { estudantes, aumentam a participação em } \\
\text { discussões e melhora no desempenho. }\end{array}$ \\
\hline $\begin{array}{l}\text { Calk, Alt, } \\
\text { Mills \& } \\
\text { Oliver } \\
(2007)\end{array}$ & $\begin{array}{l}\text { Uso de vídeos com slides lidos } \\
\text { e não interativos com o } \\
\text { professor, versus } \\
\text { representação por atores } \\
\text { pagos. }\end{array}$ & $\begin{array}{l}\text { Comparar efeitos no } \\
\text { desempenho dos } \\
\text { estudantes e } \\
\text { percepções. }\end{array}$ & $\begin{array}{l}\text { Não há diferença no desempenho entre } \\
\text { as diferentes apresentações. Também } \\
\text { não houve diferenças entre as } \\
\text { percepções, com questões como o uso de } \\
\text { exemplos do professor. }\end{array}$ \\
\hline $\begin{array}{l}\text { Fordham e } \\
\text { Hayes } \\
(2009)\end{array}$ & $\begin{array}{l}\text { A utilização de quatro cores } \\
\text { pasteis (amarelo, azul, verde e } \\
\text { rosa) e branco em papeis de } \\
\text { exercícios. }\end{array}$ & $\begin{array}{l}\text { Analisar se o } \\
\text { desempenho dos } \\
\text { estudantes difere } \\
\text { conforme a cor, a partir } \\
\text { de um estudo de } 10 \\
\text { anos e com quase } 4 \\
\text { mil estudantes. } \\
\end{array}$ & $\begin{array}{l}\text { O desempenho dos estudantes foi melhor } \\
\text { quando os exercícios estavam com as } \\
\text { cores branco e amarelo do que azul e } \\
\text { rosa. Os autores chamam a atenção dos } \\
\text { professores para evitar as cores em que o } \\
\text { estudo indica um pior desempenho. }\end{array}$ \\
\hline $\begin{array}{l}\text { Lindquist e } \\
\text { Olsen } \\
\text { (2007) }\end{array}$ & $\begin{array}{l}\text { Assistência na realização de } \\
\text { tarefas de casa com o } \\
\text { fornecimento de nenhuma } \\
\text { solução, números totais ou } \\
\text { solução completa. }\end{array}$ & $\begin{array}{l}\text { Verificar a melhora no } \\
\text { desempenho, } \\
\text { percepção de } \\
\text { aprendizagem e } \\
\text { satisfação dos } \\
\text { estudantes. }\end{array}$ & $\begin{array}{l}\text { Não foram observadas diferenças de } \\
\text { desempenho entre as diferentes } \\
\text { condições. Estudantes que não } \\
\text { receberam soluções ou gabaritos são os } \\
\text { menos satisfeitos. Contudo, esses } \\
\text { estudantes são os mais satisfeitos com } \\
\text { suas notas em testes. }\end{array}$ \\
\hline $\begin{array}{l}\text { Phillips, } \\
\text { Alford e } \\
\text { Guina } \\
(2012)\end{array}$ & $\begin{array}{l}\text { Variações de lugar e função de } \\
\text { ilustrações em livros-texto. }\end{array}$ & $\begin{array}{l}\text { Como tais variações } \\
\text { impactam o } \\
\text { aprendizado dos } \\
\text { estudantes. }\end{array}$ & $\begin{array}{l}\text { Estudantes aprendem mais com imagens } \\
\text { decorativas que precedem do que as que } \\
\text { sucedem o texto relacionado, e com } \\
\text { imagens conceituais que sucedem do que } \\
\text { as que precedem o texto relacionado. }\end{array}$ \\
\hline $\begin{array}{l}\text { Phillips e } \\
\text { Heiser } \\
\text { (2011) }\end{array}$ & $\begin{array}{l}\text { Contabilizações iniciais que } \\
\text { afetam o balanço ou também o } \\
\text { resultado. Verificação da } \\
\text { equação contábil antes ou } \\
\text { depois da realização de } \\
\text { contabilizações, ou em } \\
\text { nenhum dos casos. }\end{array}$ & $\begin{array}{l}\text { Verificar se tais } \\
\text { variações no ensino } \\
\text { das contabilizações } \\
\text { afetam o aprendizado. }\end{array}$ & $\begin{array}{l}\text { Maior sucesso inicial, de uma semana, } \\
\text { quando realizaram contabilizações e } \\
\text { consideraram o efeito na equação } \\
\text { contábil. Estudantes que realizaram } \\
\text { contabilizações num contexto mais } \\
\text { restrito, de contas do balanço apenas, } \\
\text { também obtiveram mais sucesso, o que } \\
\text { permite posterior suporte ao realizar } \\
\text { contabilizações que também envolvam o } \\
\text { resultado. }\end{array}$ \\
\hline
\end{tabular}




\begin{tabular}{l|l|l|l}
\hline Estudo & Tratamento & Objetivo & Resultados \\
\hline $\begin{array}{l}\text { Stout, } \\
\text { Bonfield e } \\
\begin{array}{l}\text { Battista } \\
(1987)\end{array}\end{array}$ & $\begin{array}{l}\text { Aulas em tempo comprimido, } \\
\text { um encontro semanal de três } \\
\text { horas, ou regulares, três } \\
\text { encontros de uma hora por } \\
\text { semana. }\end{array}$ & $\begin{array}{l}\text { Verificar o efeito no } \\
\text { desempenho e } \\
\text { avaliações dos } \\
\text { professores. }\end{array}$ & $\begin{array}{l}\text { Não se verificou diferença no } \\
\text { desempenho entre as condições, nem nas } \\
\text { avaliações atribuídas aos professores. }\end{array}$ \\
\hline $\begin{array}{l}\text { Volmer } \\
(1992)\end{array}$ & $\begin{array}{l}\text { Informações das } \\
\text { demonstrações de forma } \\
\text { gráfica versus numérica. }\end{array}$ & $\begin{array}{l}\text { Verificar o } \\
\text { entendimento acerca } \\
\text { da posição financeira } \\
\text { da empresa analisada. }\end{array}$ & $\begin{array}{l}\text { O uso de informações gráficas representa } \\
\text { um ganho de tempo de análise em } \\
\text { relação à posição da empresa, se } \\
\text { comparado às informações numéricas. }\end{array}$ \\
\hline
\end{tabular}

Fonte: elaborado pelos autores (2021).

Esse se trata do tópico mais comum como foco das pesquisas encontradas. Percebe-se, a partir da Tabela 2, que estudos que analisam efeitos de diferentes metodologias de ensino partem de inquietudes dos pesquisadores enquanto professores. Sejam seus resultados em convergência ou não com as hipóteses desenhadas, as evidências são sempre um indicador para os professores. Por exemplo, se em determinada situação as aulas precisam ser comprimidas por conta de ausências do professor para algum compromisso, Stout et al. (1987) apresentam uma evidência que não há diferença de desempenho dos estudantes em aulas que são comprimidas para um menor espaço de dias ou trabalhadas em seu período regular. Salienta-se que esse tipo de intervenção é a que mais se aproxima dos experimentos de campo, em que os professores testam metodologias na realidade das suas turmas, em sala de aula (Aguiar, 2017).

Phillips et al. (2012), como outro exemplo de procedimento para aulas, encontraram em quais lugares (antes ou depois de um conteúdo) e tipos de figuras (decorativas ou conceituais), a apresentação de figuras é mais eficiente para o entendimento do texto em questão. Partindo desse resultado, quando não há como o professor escolher um livro em tais condições, uma sugestão é a organização de apresentações do próprio professor nesse sentido. Por fim, cabe mencionar que os exemplos descritos na Tabela 2, que podem ser de ordem de apresentação de conteúdo, formas de apresentação ou até mesmo em relação a quais conteúdos, podem servir como direcionamento para professores que se questionam quanto aos métodos por si adotados.

\subsubsection{Uso de metodologias ativas}

Metodologias ativas, como o próprio nome sugere, são formas de envolver os estudantes ativamente no processo de aprendizagem, para que não recebam o conteúdo, meramente, de forma passiva. Murdoch e Guy (2002), por exemplo, realizaram sua pesquisa num contexto de metodologia ativa, a qual consistia de resolução de casos trabalhados em grupos. O objetivo da investigação foi verificar se o aprendizado ativo é diferentemente efetivo em casos de turmas grandes e pequenas. Por meio do desempenho em problemas analíticos e questões discursivas, os resultados da pesquisa indicam que o desempenho é maior em turmas pequenas do que em turmas grandes.

Outra forma de metodologia ativa é o aprendizado baseado em problemas, PBL (problem-based leearning). Breton (1999) comparou o uso do PBL com aulas tradicionais, que eram feitas por meio de apresentações, exercícios e provas, em duas turmas comparáveis na disciplina de teoria da contabilidade. Os resultados indicam que os estudantes do grupo experimental, do PBL, desenvolveram uma maior habilidade para relembrar e reusar os conteúdos que aprenderam. Assim, o estudo sugere que os estudantes que aprenderam por meio do PBL estão conscientes de ter adquirido conhecimento e habilidade os quais esperam ser mais úteis no longo prazo.

Por fim, Leauby, Szabat e Maas (2010) reportam resultados de um experimento que investigou o uso de mapas conceituais em uma disciplina de contabilidade financeira introdutória. Uma das turmas foi considerada o grupo de controle, com a utilização de aulas tradicionais, e no grupo de tratamento também foram utilizadas aulas tradicionais, mas com a adição de atividades com a realização de mapas conceituais. Ressalta-se que a designação aleatória dos participantes em grupos de tratamento e controle em experimentos é importante para inferir causa e efeito a partir das diferenças observadas entre os grupos (Shadish et al., 2002). A hipótese do estudo é que a adição dos mapas conceituais melhoraria o aprendizado, mas não houve suporte. Ao não encontrar diferenças significativas entre os grupos, o que se indica é que não há vantagem nem desvantagem com a utilização do método. Resultados adicionais indicam que os criadores de mapas o consideram como uma ferramenta valorosa para o aprendizado. Ou seja, mesmo se não resulta em superioridade no desempenho, pode ser uma forma adicional de instigar o estudo.

\subsubsection{Particularidades em disciplinas}

Em verdade, alguns dos estudos aqui citados também abordam métodos de ensino, mas se decidiu por sua apresentação aqui pelo foco em diferentes disciplinas. Assim como alguns estudos aplicados em disciplinas de contabilidade financeira são apresentados no tópico sobre métodos, o destaque aqui é para a 
disciplina de tributária. James (2000) investigou o uso de livros-texto apenas, versus o uso de uma lista de leituras, com livros e artigos. Duas turmas foram selecionadas, uma para cada condição. Os resultados evidenciam que o melhor desempenho foi observado para a turma em que foi utilizada a abordagem de um único livro.

Também relacionado à tributária, Schadewald e Limberg (1992) reportam resultados de um estudo que analisa o ensino de regras complexas de tributária por meio de textos ou por meio de textos com a adição de modelos ilustrados. A condição que recebeu modelos ilustrados obteve melhor desempenho. Os autores defendem que os benefícios desses modelos podem ser melhor percebidos quando integrados aos conteúdos textuais. Por fim, o estudo de Limberg, Schadewald e Spilker (1995) investigou a forma como os estudantes organizam seus conhecimentos em tributária. Foram analisadas duas turmas em que os métodos de ensino são diferentes, uma se trata no ensino focado na tributação por tipos de entidade e a outra por transações. Os resultados indicam que os estudantes organizam seus conhecimentos em torno da tributação por tipo de transação, sendo que tal foco aumenta com o passar do curso.

Em abordagem mais ampla, Kopp e Phillips (2005) também estudaram como estudantes organizam seus conhecimentos, mas separando duas diferentes características de disciplinas, aquelas que integram e aquelas que separam conteúdos de contabilidade financeira e gerencial. Os resultados indicam que a organização dos conteúdos afeta como os estudantes estruturam seus conhecimentos na memória, consequentemente, o desempenho em resolução de problemas é melhor quando os problemas são organizados de maneira similar às estruturas da memória. Chung e Monroe (1999) verificaram a origem de hipóteses para o desenvolvimento de julgamentos na auditoria. Hipóteses recebidas, em vez daquelas geradas pelos próprios estudantes, são mais avaliadas por uma perspectiva de confirmação do que desconfirmação, evitando assim a busca por outras possíveis conclusões.

Alguns estudos abordam tópicos mais específicos do que métodos aplicados em disciplinas inteiras. Nesse sentido, apresentam-se alguns resultados, como o de que o uso de um simulador amplia 0 entendimento de conceitos relacionados ao Balanced Scorecard-BSC (Capelo, Lopes \& Mata, 2015). Outro tópico diz respeito à Demonstração dos Fluxos de Caixa - DFC. Evidências indicam que os estudantes têm melhor desempenho quando a DFC é ensinada de maneira mais espaçada, ou seja, revista conforme a abordagem de novos conteúdos, mas não ensinada em massa, com grande abordagem de conteúdos de uma só vez (McNellis, 2015). Por fim, na designação de tarefas sobre a relação custo, volume e lucro, observa-se melhor desempenho dos estudantes quando os problemas são apresentados em linguagem do cotidiano, em vez de linguagem contábil, e com fórmulas, em vez de sem fórmulas (Johnson \& Sargent, 2013).

\subsubsection{Questões de ética}

Estudos relacionados à ética têm motivado pesquisadores na contabilidade, sendo que alguns deles observam o ensino da ética nas universidades a partir de discussões acerca da necessidade da disciplina. Nesse sentido, alguns estudos confirmam efeitos positivos do ensino da ética nos estudantes (O'Leary, 2009; Saat, Porter \& Woodbine, 2012). Entretanto, também existem achados que indicam que a capacidade de considerar aspectos éticos na tomada de decisão pode ser transitória (LaGrone, Welton \& Davis, 1996) e até de que não há aumento de raciocínio ético dos estudantes (Ponemon, 1993).

LaSalle (1997) testou se a aceitabilidade de ações questionáveis é afetada pela ordem que argumentos éticos são apresentados em sala de aula. Os resultados sugerem que estudantes de contabilidade se diferenciam de estudantes de outros cursos, em que estudantes de contabilidade tendem a dar mais importância a informações mais recentes do que às mais antigas. Fleming, Romanus e Lightner (2009) investigaram o raciocínio moral de estudantes em duas condições, aqueles que analisaram dilemas de auditoria e aqueles que analisaram dilemas de contabilidade. Aqueles na condição da auditoria demonstraram maior raciocínio moral, indicando que estudantes possuem maior conhecimento ético baseado em auditoria que não é transferido de maneira flexível para o contexto da contabilidade.

Por fim, Nouri e Shiarappa (1996) aplicaram uma prova após o início do semestre em duas turmas, sendo que em apenas uma delas foi abordado o conteúdo de ética antes da prova. Todos os estudantes tiveram pontos adicionados às suas notas da prova e foram solicitados que relatassem erros de cálculo na nota. Os resultados mostram que não houve diferença significativa entre os grupos. Assim, os autores chamam a atenção que, mesmo após a exposição de conteúdos sobre ética, os estudantes não se comportaram eticamente quando seus interesses estavam diretamente envolvidos.

Vale ressaltar que a separação de grupos de tratamento e controle por turmas pode ser questionável em relação à designação aleatória de participantes, pois a forma que as turmas forem selecionadas pode fazer com que as características gerais dos participantes sejam diferentes. Em turnos opostos de um mesmo curso, por exemplo, pode haver concorrência diferente na seleção e diferentes perfis de experiência, o que poderia enviesar os resultados. A aleatoriedade permite que explicações alheias ao modelo possam ser eliminadas (Smith, 2003), pois tal mecanismo busca deixar que os grupos sejam mais homogêneos (ex., em termos de idade, gênero, experiência), e assim, as diferenças observadas se devem apenas ao tratamento estudado. 


\subsubsection{Cooperação e trabalho em grupo}

Estudos dessa natureza analisam preferências de alunos, bem como resultados, com relação a aulas que adotam tal dinâmica. Smith e Spindle (2007) não encontraram suporte para a hipótese de que a formação de grupos compostos pelo professor com membros heterogêneos, em vez da formação decidida por eles mesmos, contribui mais para um ambiente de aprendizagem cooperativa. Seow e Shankar (2018) encontraram que estudantes com tendências de 'lobo solitário' percebem menores benefícios com trabalhos em grupos e se sentem menos confortáveis com avaliações dos pares. Contudo, aqueles que receberam um guia de habilidades para trabalho em grupo o consideram mais fácil do que aqueles que não receberam tal guia. Opdecam e Everaert (2012) encontraram que estudantes na condição de aprendizado em grupo reportaram maior satisfação e experiência positiva na disciplina do que estudantes no grupo de controle, que assistiram a aulas em formato tradicional.

Caldwell, Weishar e Glezen (1996) realizaram um estudo dividindo dois grupos, sendo o experimental com metade das aulas com o uso de técnicas de aprendizado cooperativo, e o grupo de controle com aulas tradicionais. Considerando alunos das disciplinas de princípios de contabilidade I e II, os resultados revelam que para os alunos do primeiro período as técnicas de aprendizado cooperativo geram efeitos positivos nas percepções sobre contabilidade. De maneira similar, Lancaster e Strand (2001) realizaram um experimento em que duas turmas foram submetidas à metodologia tradicional de aulas e duas turmas a aulas baseadas no aprendizado cooperativo. Os resultados, contudo, revelam que não há diferença significativa entre os grupos. Por fim, Opdecam e Everaert (2019) encontraram que alunos que optaram por participar da disciplina de aprendizado em grupo, versus a disciplina tradicional, tiveram efeitos positivos no resultado de seu aprendizado.

\subsubsection{Métodos de avaliação}

Abordam-se nesse tópico estudos que analisam formas de elaboração de avaliações e o desempenho dos estudantes. Tsui, Lau e Fong (1995) verificaram a influência dos estilos cognitivos dos estudantes sobre sua habilidade na resolução de problemas com informações ambíguas. Os resultados demonstram que estudantes com maior independência cognitiva de campo (preferem se envolver na organização e sequenciação de conteúdo), em relação àqueles com maior dependência de campo (necessitam de referências externas e conteúdo previamente organizado), apresentam melhor desempenho. Pelo fato de que a análise foi realizada por meio de questões de múltipla escolha, os autores chamam a atenção para que professores tomem cuidado com a inclusão desse tipo de questão para não desfavorecer estudantes.

Bible, Simkin e Kuechler (2008) examinaram a capacidade de avaliação de questões de múltipla escolha em relação a questões discursivas. Os resultados indicam que as questões de múltipla escolha desempenham adequadamente a avaliação pretendida. De maneira semelhante, Jonick, Schneider e Boylan (2017) examinaram o efeito de questões de múltipla escolha e discursivas sobre o desempenho de estudantes. Os resultados apontam para melhor desempenho nas questões de múltipla escolha, sendo que os autores citam razões como adivinhação (chute) e pela maior demanda cognitiva das questões discursivas.

Bay e Pacharn (2017) evidenciam resultados de um estudo que analisa o uso de avaliações em grupo, sendo que, como principal efeito positivo, há o aumento no desempenho dos estudantes em relação ao formato individual. Por outro lado, Hassan, Fox e Hannah (2014) encontraram que auto avaliações e avaliações por pares não são acuradas nem válidas, dado que essas avaliações tendem a ser superestimadas e significativamente diferentes da avaliação do professor. Murphy e Stanga (1994) avaliaram a frequência das avaliações e seu impacto no desempenho de estudantes. Foram aplicadas o dobro de avaliações para 0 grupo de tratamento em relação ao grupo de controle. Os resultados indicam melhor desempenho no grupo de tratamento para as avaliações durante o semestre, mas não para a avaliação final. Além disso, o professor obteve melhor avaliação no grupo de controle.

Phillips e Wolcott (2013) encontraram que a frequência de feedback melhora a qualidade de relatórios escritos dependendo do nível dos estudantes. Os resultados apontam que prover feedback intercalado melhora a qualidade dos relatórios de estudantes de menor desempenho, feedback sumário melhora a qualidade dos relatórios de estudantes com desempenho intermediário, e a melhoria dos relatórios de estudantes de alto desempenho independe da frequência do feedback. Finalizando, Pacharn, Bay e Felton (2013) comparam um sistema flexível de avaliação, em que os estudantes determinam os pesos das notas. Comparam-se três grupos, sendo que o de controle não possui poder de decisão sobre pesos, o segundo e terceiro, ambos de tratamento, podem alocar pesos aos conteúdos no início do período ou realocar no final. O objetivo dessa participação dos estudantes é promover habilidade de aprendizado autorregulado. Os resultados indicam que há pouca melhoria na motivação, notas e atitudes quando do comprometimento com pesos no início do período, mas quando há maior flexibilidade, ou seja, possibilidade de realocação ao final do período, esses aspectos melhoram. 


\subsubsection{Características dos estudantes}

Discutem-se aqui estudos que tenham analisado características dos estudantes, como ansiedade, experiência, diferentes culturas, entre outros. Salienta-se que as características dos estudantes não são do controle do pesquisador, assim, pode-se dizer que este tipo de estudo se enquadra como experimento natural (Aguiar, 2017). Clark e Schwartz (1989) examinaram os efeitos de um programa de modificação de comportamento na redução da ansiedade e no desempenho. Os resultados indicam redução nos níveis de ansiedade dos participantes, além de melhoria do desempenho de indivíduos com alta ansiedade. Ott, Mann e Moores (1990) analisaram se estudantes com certos traços de personalidade obtêm melhor desempenho quando instruídos a partir de dois diferentes métodos, por meio de computadores ou aulas tradicionais. Acerca do desempenho, verificou-se que não há diferença significativa entre os métodos. Tendo os traços das pessoas categorizados por sentido ou intuição e por pensamento ou sentimento, verificou-se que os participantes com traços categorizados como sentido e pensamento obtiveram melhor desempenho em aulas tradicionais, enquanto os demais obtiveram melhor desempenho com auxílio computacional.

Com relação a estilos cognitivos, Honn e Ugrin (2012) indicam evidências de que quando o estilo cognitivo dos estudantes difere das demandas cognitivas de uma tarefa, o desempenho dos estudantes é impactado negativamente. Num contexto de diferentes culturas, Almer, Brody e Masselli (2005) verificaram se há diferença na percepção de estudantes espanhóis e americanos acerca de esforços na diversidade de gênero e iniciativas amigáveis à família. Entre os resultados, é similar a percepção entre os estudantes das duas nacionalidades que homens possuem maior chance de serem contratados do que mulheres. Por outro lado, os espanhóis possuem menor crença de que as mulheres deixariam o trabalho voluntariamente do que os americanos. Também é similar a percepção de que solteiros, em comparação a pessoas casadas e com filhos, possuem maiores chances de serem contratados, promovidos e deixarem o trabalho voluntariamente.

Jones e Davidson (2007) compararam três diferentes métodos de mensuração de habilidades na resolução de problemas. Os resultados demonstram que estudantes com maior habilidade na resolução de problemas conseguiram maiores notas em questões não estruturadas do que estudantes com menor habilidade na resolução de problemas. Por fim, exterior ao âmbito escolar, o estudo de Mauldin, Zachry e Morris (2006) investigou efeitos de diferentes experiências dos estudantes sobre recrutadores. Considerando indivíduos sem experiência em contabilidade, experiência em estágio relacionado à contabilidade, experiência na área contábil e sem experiência alguma, os resultados indicam predileção por indivíduos que tenham feito estágio e, em menor grau, que tenham trabalhado na área contábil.

\subsection{Oportunidades de pesquisa no contexto brasileiro}

Como subsídios para a discussão de oportunidades de pesquisa, alguns apontamentos acerca dos estudos apresentados acima podem ser feitos. Como principal aspecto dos estudos experimentais na educação contábil, nota-se um esforço em identificar metodologias que contribuam para a melhoria do desempenho acadêmico. Pelo fato de os estudos discutidos terem utilizado experimentos como abordagem metodológica, os resultados encontrados permitem inferência de causalidade (Shadish et al., 2002). Quando há a comprovação de que algum método é significativamente superior a outro, este resultado serve de apoio ao docente em suas escolhas, mesmo no caso de quando diferenças significantes não são encontradas.

Trabalhos em grupos e metodologias ativas têm se destacado, além da importância verificada também com o ensino da ética para o contexto profissional. Destaca-se ainda a importância relacionada à investigação de características dos estudantes, no sentido de que resultados de estudos efetuados em outros países, ou até em regiões de um mesmo país, não se aplicam a todas as realidades, que diferentes culturas podem impactar no desempenho quando analisado por gênero, e que experiências profissionais podem ter efeito em um curso prático, como o de Ciências Contábeis.

No que se refere às oportunidades de pesquisa, existem evidências de que estudantes valorizam professores que conduzem e publicam pesquisas relevantes e que aplicam tais pesquisas em sala de aula (Miller, Stocks \& Proctor, 2010). Nesse sentido, além da utilização de dados a partir de pesquisas com empresas, pesquisas experimentais com alunos que tendem a melhorar a prática docente também devem ser instigadas. Schwartz, Wallin e Young (2007), por exemplo, destacam o uso de experimentos econômicos em aula, em que os alunos assumem papéis relacionados à tomada de decisão, o que contribui para a introdução intuitiva de temas complexos. Entre os temas, destacam-se a assimetria de informação, relação entre superior e subordinado, e ambientes com aumento de problemas relacionados ao controle gerencial.

Como oportunidade mais simples e, ainda assim relevante, menciona-se a replicação dos estudos mencionados. As replicações possuem como vantagens a baixa demanda no desenvolvimento do desenho da pesquisa, além da possibilidade de comparabilidade e continuidade das pesquisas originárias, adicionando robustez a argumentos e teorias. Lindsay (1995) defende que a replicação proporciona um teste crucial de confiabilidade e validade dos fatos, hipóteses e teorias, e, quando bem sucedida, a resultados previsíveis e generalizáveis. Nesse sentido, vale destacar recomendações de periódicos, como a Behavioral Research in Accounting, da associação americana de contabilidade, acerca da elaboração de estudos com caráter de replicação (Salterio, 2017). 
Outro tópico fértil para a aplicação de experimentos diz respeito à ética do profissional contábil. Para a aplicação em sala de aula, diversas fontes podem ser utilizadas. Umas delas são os casos para análise, em que os alunos podem realizar avaliações e julgamentos éticos, por meio de escalas, ao início e final da disciplina. Diferentemente da abordagem between-subjects, que é mais frequente, um estudo dessa natureza se caracterizaria como within-subjects, dado que os mesmos estudantes seriam participantes em dois momentos diferentes do estudo (Ver Aguiar, 2017). Um estudo nesse sentido seria capaz de avaliar qual a evolução dos estudantes acerca do comportamento ético com a disciplina. O Código de Ética Profissional do Contador também pode ser usado para a construção de casos que envolvam o comportamento ético e o julgamento dos estudantes em situações que envolvam dilemas profissionais.

De maneira geral, diferentes metodologias de ensino também podem ser testadas, e, em especial, as metodologias ativas, dado o apelo que elas têm recebido. Esse apelo é decorrente da necessidade de, segundo Coutelle (2017), o professor despertar a motivação do aluno em aprender. Além da possibilidade de seu uso por parte dos professores em sala, interessa também o estudo científico acerca de seus efeitos na aprendizagem. No contexto do ensino em contabilidade no Brasil, Leal, Miranda e Nova (2019) apresentam diversas possibilidades de metodologias ativas a serem aplicadas em sala. Por isso, cabe ao professor, interessado no uso de métodos diferentes dos mais tradicionais, a aplicação de metodologias ativas, bem como o estudo de sua efetividade por meio de experimentos. Testes por meio de experimentos são, mais do que simples convicções, a comprovação da relação de causa e efeito, seja no desempenho, satisfação dos alunos, ou outra variável que o pesquisador tenha interesse em verificar.

Dentre metodologias ativas que têm motivado estudos, destacam-se aqui a contação de histórias, sala de aula invertida e uso de jogos. De acordo com Taylor, Marrone, Tayar e Mueller (2017), a contação de histórias ajuda na explicação de conteúdos complexos, as quais aguçam a atenção dos estudantes e permitem melhor entendimento do ambiente real. Segundo os autores, comparações entre vídeos que usam metáforas ou não podem ser comparados para verificação do efeito isolado no desempenho. Bergner e Brooks (2017) verificaram o efeito da utilização do jogo Monopoly para revisão para provas, sendo que tal efeito é significativamente positivo nas notas, se comparado aos métodos tradicionais ou na ausência de revisão. Nesse contexto, a utilização de jogos de cartas, frequentemente praticados pelos alunos, podem de alguma forma ser adotados para o ensino, bem como para a investigação de seus efeitos no aprendizado. Por fim, a sala de aula invertida busca maior envolvimento e aprendizado dos estudantes, diferindo do tradicional método cara-a-cara (Williams, Horner \& Allen, 2019). Pesquisas experimentais, nesse caso, também seriam aplicáveis no sentido de comparar, por exemplo, o desempenho de turmas submetidas a tal método, em relação aos métodos mais tradicionais de aula.

Mudanças curriculares nos cursos também são propícias para a aplicação de experimentos. Por exemplo, caso alguma disciplina seja realocada mais ao início ou fim do curso, pode-se avaliar o desempenho nos dois casos. Quando possível, a aplicação de experimento antes da mudança curricular pode contribuir para testar possíveis impactos das mudanças pretendidas. Adicionalmente, estudos que explorem diferentes formas de avaliação e seus efeitos na aprendizagem dos estudantes possuem potencialidade de produzir conhecimentos que se conjuguem a outros - sobre eficiência e efetividade de métodos de ensino, por exemplo - de modo a subsidiar decisões pedagógicas que impliquem em aprimoramento no processo de ensino e aprendizagem.

Outro aspecto a ser investigado se refere ao uso de tecnologias. É uma área que permeia a história do ensino em contabilidade e que, em tempos de aumento da participação do ensino a distância na educação em contabilidade e de intensividade de uso e disponibilidade de recursos tecnológicos digitais, possibilita explorar diversas nuances e direções. Se entre as décadas de 1980 e 1990 o uso de computadores era o principal objetivo desses estudos, na atualidade, novos aplicativos, plataformas e ambientes virtuais diversificados para o ensino e metodologias ativas podem ser conjugados em propostas de experimentos que merecem atenção acerca de seus impactos sobre o aprendizado, interesse e satisfação dos estudantes.

\section{Considerações Finais}

O objetivo deste estudo foi descrever, a partir de revisão narrativa de literatura especificamente selecionada, estudos nacionais e internacionais no campo da educação contábil que utilizaram método experimental e quase-experimental. Adicionalmente, apresentar oportunidades de pesquisas nesse campo com o uso do método. Um aspecto que chamou a atenção ao longo da realização deste estudo foi que nos periódicos nacionais de contabilidade são escassas as pesquisas que usaram o método experimental - tanto especificamente sobre o tema educação em contabilidade quanto, de forma geral, nos demais temas da contabilidade.

Nos periódicos internacionais selecionados, experimentos aparecem mais frequentemente, apesar de ainda terem participação menor no conjunto das pesquisas em educação contábil. Todavia, desde a década de 1990 pesquisas em educação contábil utilizando experimentos tem regularidade em publicações. Nota-se, também no âmbito internacional, evolução das pesquisas experimentais em diversificadas temáticas, que incluem testes com a comparação de gravuras com conteúdo textuais, uso de vídeos, métodos de avaliações, 
sequência de conteúdo, habilidades na tomada de decisão, dentre outros. Geralmente, o foco dos pesquisadores foi verificar efeitos no desempenho e na satisfação dos alunos.

No contexto brasileiro há um registro da década de 1990, seguido de um hiato. Somente em 2003 surge uma nova publicação de experimento em educação contábil em periódico nacional. Em decorrência dessa escassez, faz-se necessário o desenvolvimento de mais estudos e publicações de pesquisas experimentais. Quanto aos temas, direcionaram-se à identificação de habilidades do raciocínio crítico dos alunos, em diferentes disciplinas, assim como na utilização de ambiente virtual. Há ainda pesquisas que são direcionadas à aplicação de jogos de empresas e outras que se relacionam à eficácia de aprendizagem, desempenho acadêmico e satisfação dos alunos. Verifica-se que, embora com objetivos semelhantes, pela quantidade as pesquisas internacionais tendem a ser mais variadas.

A partir desse contexto, algumas conclusões podem ser elencadas. A primeira delas é que a escassez de experimentos na educação contábil prejudica a construção de uma base científica para a área, justamente pela ausência de inferências de causa e efeito e a consequente falta de adoção de práticas mais adequadas para a área, desde o planejamento de currículo até as formas de avaliação. Outro aspecto se relaciona à referida estagnação da pesquisa na educação contábil, em que se sugere a maior adoção de estudos experimentais, mas tal tendência não é percebida internacionalmente, tampouco nacionalmente. Por fim, a dependência majoritária de levantamentos pode levar a conclusões enviesadas do que é mais eficiente no processo de aprendizagem, em detrimento do que é mais agradável aos estudantes.

Nota-se também que é fértil o campo para a aplicação de experimentos no contexto da educação contábil, especialmente pela escassez de estudos experimentais no Brasil. Portanto, apresentam-se algumas oportunidades para desenvolvimento científico da área. Como ponto de partida aos pesquisadores, recomenda-se a replicação de estudos já efetuados. Estudos a partir do uso de diferentes metodologias para ensino, tecnologias, metodologias ativas e metodologias específicas para disciplinas com maior exigência cognitiva também são recomendados. Em decorrência de mudanças no mercado de trabalho, e consequente exigência de novas habilidades, mudanças curriculares também podem ser testadas antes de serem implementadas. Aspectos como comportamento ético e formas de avaliação também merecem atenção.

Mencionam-se aqui, por fim, possíveis resultados/implicações com o desenvolvimento de experimentos. Como resultados para a área, destaca-se que os professores, com suas experiências em sala, podem ter a percepção de métodos ou aspectos a serem melhorados no processo de ensino-aprendizagem, para assim efetuarem estudos que contribuem tanto para a comunidade acadêmica, quanto para sua própria atividade. Porém, deve-se atentar também para algumas dificuldades no desenvolvimento dos estudos. Enquanto poucos estudos com a metodologia experimental são realizados, menor é a rede de avaliadores capacitados para contribuírem com o desenvolvimento da área e da qualidade dos estudos.

Em termos de limitação, este estudo apresenta os seguintes fatores. O primeiro relaciona-se com seu delineamento - pesquisa bibliográfica classificada entre a narrativa e a sistemática, revisional e interpretativa. Ainda que a investigação tenha ocorrido pautada por protocolo e com adoção de critérios para a seleção do corpus, há a possibilidade de que vieses tenham ocorrido. Nesse sentido, os resultados devem ser tomados com ressalvas, principalmente quanto sua abrangência e generalização. $O$ segundo fator se refere aos elementos analisados em cada estudo, em que não há a possibilidade de aprofundar aspectos como tipo do experimento, design, variáveis dependentes e fatorial para cada um.

O último fator relaciona-se com a opção por investigar somente periódicos específicos do campo contábil - tanto no levantamento nacional quanto no internacional. O que, por sua vez, exclui a inserção de estudos que estejam publicados em periódicos de outras áreas de conhecimento, como os da área da educação, por exemplo. E isso se mostra um fator limitante em certa medida. Além disso, deve-se mencionar a delimitação de periódicos internacionais da área de educação em contabilidade, excetuando-se assim outros importantes periódicos internacionais da área contábil da amostra dos artigos. Contudo, tal opção se deu por considerar que, em se tratando de estudos sobre educação em contabilidade, o campo de divulgação científica que potencialmente provoca maior alcance dentro do campo científico contábil é o das revistas científicas específicas sobre contabilidade. Além de ultrapassar tais limitações, sugere-se que estudos futuros façam análise bibliométrica, identificando autores mais prolíficos, impacto dos estudos (citações) e análise da evolução temporal das temáticas estudadas, com o intuito de identificar tendências.

\section{Referências}

Abeysekera, I. (2015). The Role of Work-Integrated Learning in Student Preferences of Instructional Methods in an Accounting Curriculum. Asia-Pacific Journal of Cooperative Education, 16(1), 71-86.

Aguiar, A. B. (2017). Pesquisa experimental em contabilidade: propósito, desenho e execução. Advances in Scientific and Applied Accounting, 10(2), 224-244. http://dx.doi.org/10.14392/asaa.2017100206

Aguiar, A. B. de. (2018). O pequeno mundo da pesquisa em contabilidade gerencial no Brasil: discussão sobre desenhos alternativos de pesquisa. Revista de Contabilidade e Organizações, 12, e151933.

https://doi.org/10.11606/issn.1982-6486.rco.2018.151933 
Alkafaji, Y., \& Schroeder, N. (1986). Manual vs. computerized practice sets: A test for differences. Journal of Accounting Education, 4(2), 19-25. https://doi.org/10.1016/0748-5751(86)90003-5

Almer, E. D., Brody, R. G., \& Masselli, J. J. (2005). A cross-cultural analysis of student perceptions of gender diversity, family status and hiring practices in Spain and the United States. Global Perspectives on Accounting Education, 2(1), 37-51.

Anderson, J. A., \& Boynton, W. C. (1992). Managing the intermediate accounting overload: An experiment. Journal of Accounting Education, 10(2), 297-307. https://doi.org/10.1016/0748-5751(92)90004$\underline{\mathrm{O}}$

Apostolou, B., Dorminey, J. W., \& Hassell, J. M. (2020). Accounting education literature review (2019). Journal of Accounting Education, 100670. https://doi.org/10.1016/i.jaccedu.2020.100670

Apostolou, B., Dorminey, J. W., Hassell, J. M., \& Hickey, A. (2019). Accounting education literature review (2018). Journal of Accounting Education, 47, 1-27. https://doi.org/10.1016/j.jaccedu.2019.02.001

Apostolou, B., Dorminey, J. W., Hassell, J. M., \& Rebele, J. E. (2015). Accounting education literature review (2013-2014). Journal of Accounting Education, 33 (2), 69-127. https://doi.org/10.1016/j.jaccedu.2015.04.001

Apostolou, B., Dorminey, J. W., Hassell, J. M., \& Rebele, J. E. (2016). Accounting education literature review (2015). Journal of Accounting Education, 35, 20-55. https://doi.org/10.1016/i.jaccedu.2016.03.002

Apostolou, B., Dorminey, J. W., Hassell, J. M., \& Rebele, J. E. (2017). Accounting education literature review (2016). Journal of Accounting Education, 39, 1-31. https://doi.org/10.1016/.j.jaccedu.2017.03.001

Apostolou, B., Dorminey, J. W., Hassell, J. M., \& Rebele, J. E. (2018). Accounting education literature review (2017). Journal of Accounting Education, 43, 1-23. https://doi.org/10.1016/j.jaccedu.2018.02.001

Apostolou, B., Dorminey, J. W., Hassell, J. M., \& Watson, S. F. (2013). Accounting education literature review (2010-2012). Journal of Accounting Education, 31 (2), 107-161.

https://doi.org/10.1016/j.jaccedu.2013.03.001

Bay, D., \& Pacharn, P. (2017). Impact of group exams in a graduate intermediate accounting class. Accounting Education, 26(4), 316-334. https://doi.org/10.1080/09639284.2017.1292465

Benke Jr, R. L., \& Street, D. L. (1992). Accounting education research methodology. Accounting Education, 1(1), 33-45. https://doi.org/10.1080/09639289200000004

Bergner, J., \& Brooks, M. (2017). The efficacy of using Monopoly to improve undergraduate students' understanding of the accounting cycle. Advances in accounting education: Teaching and curriculum innovations, 20, 33-50. https://doi.org/10.1108/S1085-462220170000020003

Bible, L., Simkin, M. G., \& Kuechler, W. L. (2008). Using multiple-choice tests to evaluate students' understanding of accounting. Accounting Education: an international journal, 17(S1), S55-S68. https://doi.org/10.1080/09639280802009249

Borges, R. M. R., \& Moraes, R. (1998). Educação em Ciências nas séries iniciais. Porto Alegre: Sagra Luzzatto.

Boritz, J. E., Borthick, A. F., \& Presslee, A. (2012). The effect of business process representation type on assessment of business and control risks: Diagrams versus narratives. Issues in Accounting Education, 27(4), 895-915. https://doi.org/10.2308/iace-50144

Breton, G. (1999). Some empirical evidence on the superiority of the problem-based learning (PBL) method. Accounting Education, 8(1), 1-12. https://doi.org/10.1080/096392899331008

Brink, A. G. (2013). The impact of pre-and post-lecture quizzes on performance in Intermediate Accounting II. Issues in Accounting Education, 28(3), 461-485. https://doi.org/10.2308/iace-50445 
Caldwell, M. B., Weishar, J., \& William, G. (1996). The effect of cooperative learning on student perceptions of accounting in the principles courses. Journal of Accounting Education, 14(1), 17-36.

https://doi.org/10.1016/0748-5751(95)00032-1

Calk, R., Alt, K., Mills, S. K., \& Oliver, R. (2007). The effective delivery of a streaming video course lecture. Accounting Education: An International Journal, 16(1), 81-93.

https://doi.org/10.1080/09639280600843393

Capelo, C., Lopes, A., \& Mata, A. (2015). A simulation-based approach for teaching the systems perspective of strategic performance management. Accounting Education, 24(1), 1-26.

https://doi.org/10.1080/09639284.2014.979430

Carvalho Júnior, C. V. de O., Rocha, J. S. da, \& Bruni, A. L. (2010). Efeito framing em decisões gerenciais e aprendizado formal de controladoria: um estudo experimental. RIC - Revista de Informação Contábil, 4(3), 35-56. https://doi.org/10.34629/ric.v4i3.35-56

Chung, J., \& Monroe, G. S. (1999). The effects of counterexplanation and source of hypothesis on developing audit judgment. Accounting Education, 8(2), 111-126. https://doi.org/10.1080/096392899330964

Clark, C. E., \& Schwartz, B. N. (1989). Accounting anxiety: An experiment to determine the effects of an intervention on anxiety levels and achievement of introductory accounting students. Journal of Accounting education, 7(2), 149-169. https://doi.org/10.1016/0748-5751(89)90002-X

Costa, F., \& Martins, G. de A. (2016). Características epistemológicas de publicações científicas em Contabilidade: evidências de um cenário produtivista. Revista Contemporânea De Contabilidade, 13(29), 3368. https://doi.org/10.5007/2175-8069.2016v13n29p33

Coutelle, J. E. (2017). Aprender é uma decisão do aluno. Revista Ensino Superior, 222.

Frezatti, F., de Aguiar, A. B., de Araujo Wanderley, C., \& Malagueño, R. (2015). A pesquisa em contabilidade gerencial no Brasil: desenvolvimento, dificuldades e oportunidades. Revista Universo Contábil, 11(1), 47-68. https://doi.org/10.4270/ruc.2015103

Fleming, D. M., Lightner, S. M., \& Romanus, R. N. (2009). The effect of professional context on accounting students' moral reasoning. Issues in accounting education, 24(1), 13-30.

https://doi.org/10.2308/iace.2009.24.1.13

Fordham, D. R., \& Hayes, D. C. (2009). Worth repeating: Paper color may have an effect on student performance. Issues in Accounting Education, 24(2), 187-194. https://doi.org/10.2308/iace.2009.24.2.187

Hartmann, F. G. H. (2017). Pesquisa contábil: entre a ciência natural e a prática. Revista Contabilidade \& Finanças, 28(73), 7-10. https://doi.org/10.1590/1808-057x201790160

Hassan, O. A., Fox, A., \& Hannah, G. (2014). Self-and peer-assessment: evidence from the accounting and finance discipline. Accounting Education, 23(3), 225-243. https://doi.org/10.1080/09639284.2014.905259

Hesford, J. W., Lee, S. H. S., Van der Stede, W. A., \& Young, S. M. (2006). Management accounting: a bibliographic study. In: Chapman, C. S., Hopwood, A. G., \& Shields, M. D. (Eds.), Handbooks of management accounting research, v. 1, Oxford: Elsevier, 3-26.

Homero Jr., P. F. (2016). Crítica metodológica e epistemológica de pesquisas contábeis experimentais publicadas no Brasil. Revista de Educação e Pesquisa em Contabilidade (REPeC), 10(2), 220-233. https://doi.org/10.17524/repec.v10i2.1378

Honn, D. D., \& Ugrin, J. C. (2012). The effects of cognitive misfit on students' accounting task performance. Issues in Accounting Education, 27(4), 979-998. https://doi.org/10.2308/iace-50258

James, S. (2000). Teaching tax principles and policy: comparing the single textbook and wider reading approaches. Accounting Education, 9(3), 281-289. https://doi.org/10.1080/09639280010017239

Johnson, B. G., \& Sargent, C. S. (2014). Impact of formulas, language and instruction on student performance on cost-volume-profit problems. Accounting Education, 23(1), $22-41$.

https://doi.org/10.1080/09639284.2013.824702 
Jones, S. H., \& Davidson, R. A. (2007). Measuring the problem-solving abilities of accounting and other business students: a comparison and evaluation of three methods. Accounting Education: an international journal, 16(1), 65-79. https://doi.org/10.1080/09639280600826034

Jonick, C., Schneider, J., \& Boylan, D. (2017). The effect of accounting question response formats on student performance. Accounting Education, 26(4), 291-315.

https://doi.org/10.1080/09639284.2017.1292464

Kopp, L. S., \& Phillips, F. (2005). Integrating accounting topics within or across functions: Effects on students' structure and use of knowledge. Journal of Accounting Education, 23(3), 170-188.

https://doi.org/10.1016/i.jaccedu.2005.08.002

Laffin, M., \& Gomes, S. M. da S. (2016). Formação do professor de contabilidade: o tema em debate. Arquivos Analíticos de Políticas Educativas, 24(77), 1-31. http://dx.doi.org/10.14507/epaa.24.2372

LaGrone, R. M., Welton, R. E., \& Davis, J. R. (1996). Are the effects of accounting ethics interventions transitory or persistent? Journal of Accounting Education, 14(3), 259-276. https://doi.org/10.1016/0748$\underline{5751(96) 00022-X}$

Lancaster, K. A., \& Strand, C. A. (2001). Using the team-learning model in a managerial accounting class: An experiment in cooperative learning. Issues in Accounting Education, 16(4), 549-567.

https://doi.org/10.2308/iace.2001.16.4.549

LaSalle, R. E. (1997). Presentation order effects on accounting students' ethical judgments. Journal of Accounting Education, 15(1), 19-38. https://doi.org/10.1016/S0748-5751(96)00047-4

Leal, E. A., Miranda, G. J., \& Nova, S. P. C. C. (2019). Revolucionando a sala de aula: como envolver o estudante aplicando as técnicas de metodologias ativas de aprendizagem. 1. ed. 3. Reimpr. São Paulo: Atlas, 2019.

Leauby, B. A., Szabat, K. A., \& Maas, J. D. (2010). Concept mapping-An empirical study in introductory financial accounting. Accounting Education: an international journal, 19(3), 279-300.

https://doi.org/10.1080/09639280903412334

Lima, K. E. C., \& Teixeira, F. M. (2005). A epistemologia e a história do conceito experimento/experimentação e seu uso em artigos científicos sobre ensino das ciências. Anais do VII Encontro Nacional de Pesquisa em Educação em Ciências. Campinas, SP.

Limberg, S. T., Schadewald, M. S., \& Spilker, B. C. (1995). Organizing tax instruction: Evidence regarding how students organize tax knowledge. Journal of Accounting Education, 13(1), 45-58.

https://doi.org/10.1016/0748-5751(94)00022-0

Lindquist, T. M., \& Olsen, L. M. (2007). How much help, is too much help? An experimental investigation of the use of check figures and completed solutions in teaching intermediate accounting. Journal of Accounting Education, 25(3), 103-117. https://doi.org/10.1016/j.jaccedu.2007.07.001

Lindsay, R. M. (1995). Reconsidering the status of tests of significance: An alternative criterion of adequacy. Accounting, Organizations and Society, 20(1), 35-53. https://doi.org/10.1016/03613682(93)E0004-Z

Marriott, N. (1992). The effectiveness of using spreadsheets to teach financial accounting. Accounting Education, 1(2), 137-150. https://doi.org/10.1080/09639289200000024

Marriott, N., \& Mellett, H. (1994). Introducing spreadsheets into an intermediate financial accounting course: the results of a quasi-experiment. Accounting Education, 3(4), 297-311.

https://doi.org/10.1080/09639289400000029

Matos, E. B. S. de, Niyama, J. K., Fernandes, J. L. T., \& Botelho, D. R. (2012). Um estudo sobre a pesquisa em educação contábil em periódicos internacionais: Temáticas envolvendo as normas internacionais de contabilidade. ConTexto, 12(22), 59-73.

Mauldin, S., Zachry, B., \& Morris, J. L. (2006). Does student work experience affect CPA firm recruiting decisions? The Accounting Educators' Journal, 16, 41-51. 
Mclnnes, W. M., Pyper, D., Van Der Meer, R., \& Wilson, R. A. (1995). Computer-aided learning in accounting; educational and managerial perspectives. Accounting Education, 4(4), 319-334. https://doi.org/10.1080/09639289500000037

McNellis, C. J. (2015). Re-conceptualizing instruction on the statement of cash flows: The impact of different teaching methods on intermediate accounting students' learning. Advances in Accounting Education, 17, 115. https://doi.org/10.1108/S1085-462220150000017017

Miller, K. C., Stocks, M. H., \& Proctor, T. Y. (2010). Publishing and utilizing relevant research in accounting: The impact on the perception of effective teaching. Advances in Accounting Education, 11, 221-246. https://doi.org/10.1108/S1085-4622(2010)0000011013

Miranda, G. J., Santos, L. de Al. A., Nova, S. P. de C. C., \& Cornacchione Júnior, E. B. (2013). A pesquisa em Educação Contábil: produção científica e preferências de doutores no período de 2005 a 2009. Revista Contabilidade \& Finanças, 24(61), 75-88. https://doi.org/10.1590/S1519-70772013000100008

Murdoch, B., \& Guy, P. W. (2002). Active learning in small and large classes. Accounting Education, 11(3), 271-282. https://doi.org/10.1080/0963928021000031448

Murphy, D. P., \& Stanga, K. G. (1994). The effects of frequent testing in an income tax course: An experiment. Journal of Accounting Education, 12(1), 27-41. https://doi.org/10.1016/0748-5751(94)90017-5

Nouri, H., \& Shahid, A. (2005). The effect of PowerPoint presentations on student learning and attitudes. Global Perspectives on Accounting Education, 2, 53-75.

Nouri, H., \& Shahid, A. (2008). The effects of PowerPoint lecture notes on student performance and attitudes. The Accounting Educators' Journal, 18, 103-117.

Nouri, H., \& Shiarappa, B. (1996). An empirical examination of senior accounting students' ethical reaction to grade inflation. Accounting Education, 5(1), 17-24. https://doi.org/10.1080/09639289600000002

O'Leary, C. (2009). An empirical analysis of the positive impact of ethics teaching on accounting students. Accounting Education: An International Journal, 18(4-5), 505-520.

https://doi.org/10.1080/09639280802532158

Opdecam, E., \& Everaert, P. (2012). Improving student satisfaction in a first-year undergraduate accounting course by team learning. Issues in Accounting Education, 27(1), 53-82. https://doi.org/10.2308/iace-10217

Opdecam, E., \& Everaert, P. (2019). Choice-based learning: lecture-based or team learning? Accounting Education, 28(3), 239-273. https://doi.org/10.1080/09639284.2019.1570857

Ott, R. L., Mann, M. H., \& Moores, C. T. (1990). An empirical investigation into the interactive effects of student personality traits and method of instruction (lecture or CAI) on student performance in elementary accounting. Journal of Accounting Education, 8(1), 17-35. https://doi.org/10.1016/0748-5751(90)90018-3

Pacharn, P., Bay, D., \& Felton, S. (2013). The impact of a flexible assessment system on students' motivation, performance and attitude. Accounting Education, 22(2), 147-167.

https://doi.org/10.1080/09639284.2013.765292

Passos, I. C., Cornacchione Júnior, E. B., Gaio, L. E., \& Brito, E. de. (2016a). Raciocínio crítico em ambientes virtuais. Revista de Contabilidade e Organizações, 10(26), 78-88.

https://doi.org/10.11606/rco.v10i26.111420

Passos, I. C., Cornacchione Júnior, E. B., Gaio, L. E., Brito, E. de, \& Mori, J. S. (2016b). Raciocínio crítico e jogos de empresas. Revista Contabilidade e Controladoria, 8(3), 82-94.

Passos, I. C., Cornacchione Júnior, E. B., Gaio, L. E., \& Mori, J. S. (2015). Raciocínio crítico dos alunos de graduação em Ciências Contábeis da FEA-USP: uma aplicação do modelo instrucional de Richard Paul. Contabilidade Vista \& Revista, 26(3), 25-48. 
Pereira, I. V., \& Silva, C. A. T. (2018). Aprendizagem cooperativa como estratégia de ensino para a contabilidade: habilidades intelectuais da taxonomia do domínio cognitivo. Revista Ambiente Contábil, 10(1), 54-70. https://doi.org/10.21680/2176-9036.2018v10n1ID12296

Phillips, F., Alford, S. J., \& Guina, S. (2012). Illustrations in financial accounting textbooks: Function and placement interact to affect student learning. Issues in Accounting Education, 27(4), 999-1017. https://doi.org/10.2308/iace-50243

Phillips, F., \& Heiser, L. (2011). A field experiment examining the effects of accounting equation emphasis and transaction scope on students learning to journalize. Issues in Accounting Education, 26(4), 681-699. https://doi.org/10.2308/iace-50051

Phillips, F., \& Wolcott, S. (2014). Effects of interspersed versus summary feedback on the quality of students' case report revisions. Accounting Education, 23(2), 174-190. https://doi.org/10.1080/09639284.2013.847328

Pituch, K. A., Murphy, D. L., \& Tate, R. L. (2009). Three-level models for indirect effects in school-and classrandomized experiments in education. The Journal of Experimental Education, 78(1), 60-95.

https://doi.org/10.1080/00220970903224685

Ponemon, L. A. (1993). Can ethics be taught in accounting? Journal of Accounting Education, 11(2), 185209. https://doi.org/10.1016/0748-5751(93)90002-Z

Pozzebon, M., \& Petrini, M. de. (2013) Critérios para condução e avaliação de pesquisas qualitativas de natureza crítico-interpretativa. In: Takahashi, A. R. W. (org.) (2013) Pesquisa qualitativa em administração: fundamentos, métodos e usos no Brasil. São Paulo. Atlas.

Quintana, A. C., \& Afonso, L. E. (2018). Tecnologias na educação: há impacto no desempenho acadêmico?. Revista Universo Contábil, 14(1), 07-28. https://doi.org/10.4270/RUC.2018101

Raudenbush, S. W., \& Schwartz, D. (2020). Randomized experiments in education, with implications for multilevel causal inference. Annual Review of Statistics and Its Application, 7, 177-208.

https://doi.org/10.1146/annurev-statistics-031219-041205

Rebele, J. E., \& Pierre, E. K. S. (2015). Stagnation in accounting education research. Journal of Accounting Education, 33(2), 128-137. https://doi.org/10.1016/i.jaccedu.2015.04.003

Rebele, J. E., Stout, D. E., \& Hassell, J. M. (1991). A review of empirical research in accounting education: 1985-1991. Journal of Accounting Education, 9(2), 167-231. https://doi.org/10.1016/0748-5751(91)90003-A

Rebele, J. E., \& Tiller, M. G. (1986). Empirical research in accounting education: A review and evaluation. In A. C. Bishop, E. K. St Pierre, and R. L. Benke (eds.), Research in accounting education (pp. 1-54). Harrisonburg, VA: Center for Research in Accounting Education, James Madison University.

Saat, M. M., Porter, S., \& Woodbine, G. (2012). A longitudinal study of accounting students' ethical judgement making ability. Accounting Education, 21(3), 215-229.

https://doi.org/10.1080/09639284.2011.562012

Salterio, S. (2017). Initial Thoughts and Guidance on Publishing Replications in BRIA. Behavioral Research in Accounting. Disponível em:

https://aaahq.org/Portals/0/Users/029/13/3613/BRIA\%20replication\%20guideance.pdf

Sampieri, R. H., Collado, C. F., \& Lucio, M. P. B. (2013). Metodologia de pesquisa. 5. ed. Porto Alegre: Penso.

Sangster, A., Fogarty, T., Stoner, G., \& Marriott, N. (2015). The Impact of Accounting Education Research. Accounting Education, 24(5), 423-444. https://doi.org/10.1080/09639284.2015.1091740

Santos, R. V. dos (2003). "Jogos de empresas" aplicados ao processo de ensino e aprendizagem de contabilidade. Revista Contabilidade \& Finanças - USP, 14(31), 78-95. https://doi.org/10.1590/S1519$\underline{70772003000100006}$ 
Schadewald, M., \& Limberg, S. (1992). Using pictorial models to teach complex tax rules: An experimental investigation. Journal of Accounting Education, 10(1), 133-149. https://doi.org/10.1016/0748-5751(92)90021$\underline{\mathrm{V}}$

Schwartz, S. T., Wallin, D. E., \& Young, R. A. (2007). Economic experiments for the management accounting classroom. Issues in Accounting Education, 22(3), 515-534. https://doi.org/10.2308/iace.2007.22.3.515

Seow, J. L., \& Shankar, P. G. (2018). Effects of team-skills guidance on accounting students with lone wolf tendencies. Accounting Education, 27(3), 309-332. https://doi.org/10.1080/09639284.2018.1476892

Shadish, W. R., Cook, T. D., \& Campbell, D. T. (2002). Experimental and quasi-experimental designs for generalized causal inference. Boston: Houghton Mifflin.

Silva, C., Ferreira, L., Leal, E., \& Miranda, G. (2019). Formação Docente na Área Contábil: Contribuições da Disciplina de Metodologia do Ensino oferecida na Pós-Graduação Stricto Sensu. Sociedade, Contabilidade e Gestão, 14(3), 144-162. https://doi.org/10.21446/scg ufri.v0i0.23062

Sithole, S. T. (2018). Instructional strategies and students' performance in accounting: an evaluation of those strategies and the role of gender. Accounting Education, 27(6), 613-631.

https://doi.org/10.1080/09639284.2017.1361852

Smith, J. van der L., \& Spindle, R. M. (2007). The impact of group formation in a cooperative learning environment. Journal of Accounting Education, 25(4), 153-167. https://doi.org/10.1016/i.jaccedu.2007.09.002

Smith, Malcolm. (2003). Research methods in accounting. London: SAGE Publications.

Stout, D. E., Bonfield, E. H., \& Battista, M. S. (1987). Additional experimental evidence on the relationship between class meeting time compression and accounting student performance and evaluations. Journal of Accounting Education, 5(2), 339-348. https://doi.org/10.1016/0748-5751(86)90006-0

Street, D. L. (1995). Controlling extraneous variables in experimental research: A research note. Accounting Education, 4(2), 169-188. https://doi.org/10.1080/09639289500000020

Taylor, M., Marrone, M., Tayar, M., \& Mueller, B. (2018). Digital storytelling and visual metaphor in lectures: a study of student engagement. Accounting Education, 27(6), 552-569. https://doi.org/10.1080/09639284.2017.1361848

Teixeira, P. M. M., \& Megid Neto, J. (2017). Uma proposta de tipologia para pesquisas de natureza interventiva. Ciência \& Educação (Bauru), 23(4), 1055-1076. https://doi.org/10.1590/1516731320170040013

Teodoro, I. P. P., Rebouças, V. de C. F., Thorne, S. E., Souza, N. K. M. de, Brito, L. S. A. de, \& Alencar, A. M. P. G. (2018). Descrição interpretativa: uma abordagem metodológica viável para a pesquisa em enfermagem. Escola Anna Nery, 22(3), e20170287. https://doi.org/10.1590/2177-9465-ean-2017-0287

Triviños, A. N. S. (1987). Introdução à pesquisa em ciências sociais: a pesquisa qualitativa em educação. São Paulo: Atlas.

Tsui, J. S., Lau, T. S., \& Fong, S. C. (1995). Analysis of accounting students' performance on multiple-choice examination questions: a cognitive style prespective. Accounting Education, 4(4), 351-357.

https://doi.org/10.1080/09639289500000039

Vendramin, E., \& Araujo, A. (2016). Contribuição ao entendimento da formação da linha de pesquisa na área de ensino contábil no Brasil. Revista Universo Contábil, 12(1), 66-86.

https://doi.org/10.4270/ruc.2016104

Volmer, F. G. (1992). Effect of graphical presentations on insights into a company's financial position: an innovative educational approach to communicating financial information in financial reporting. Accounting Education, 1(2), 151-170. https://doi.org/10.1080/09639289200000025

Whitehurst, G. J. (2012). The value of experiments in education. Education Finance and Policy, 7(2), 107123. https://doi.org/10.1162/EDFP a 00058 
Williams, B., Horner, C., \& Allen, S. (2019). Flipped v's traditional teaching perspectives in a first year accounting unit: an action research study. Accounting Education, 28(4), 333-352.

https://doi.org/10.1080/09639284.2019.1609536

\section{NOTAS}

\section{AGRADECIMENTOS}

Não se aplica.

\section{CONTRIBUIÇÃO DE AUTORIA}

Concepção e elaboração do manuscrito: R. Suave, S. M. L. Altoé, M. M. Ferreira

Coleta de dados: R. Suave

Análise de dados: R. Suave, S. M. L. Altoé

Discussão dos resultados: $R$. Suave

Revisão e aprovação: R. Suave, S. M. L. Altoé, M. M. Ferreira

\section{CONJUNTO DE DADOS DE PESQUISA}

Todo o conjunto de dados que dá suporte aos resultados deste estudo foi publicado no próprio artigo.

\section{FINANCIAMENTO}

Não se aplica.

\section{CONSENTIMENTO DE USO DE IMAGEM}

Não se aplica.

\section{APROVAÇÃO DE COMITÊ DE ÉTICA EM PESQUISA}

Não se aplica.

\section{CONFLITO DE INTERESSES}

Não se aplica.

\section{LICENÇA DE USO}

Os Direitos Autorais para artigos publicados neste periódico são do autor, com direitos de primeira publicação para a Revista. Em virtude de aparecerem nesta Revista de acesso público, os artigos são de uso gratuito, com atribuições próprias, em aplicações educacionais, de exercício profissional e para gestão pública. A Revista adotou a licença Creative Commons Atribuição 4.0 Internacional - CC BY NC ND. Esta licença permite acessar, baixar (download), copiar, imprimir, compartilhar, reutilizar e distribuir os artigos desde que com a citação da fonte, atribuindo os devidos créditos de autoria. Nesses casos, nenhuma permissão é necessária por parte dos autores ou dos editores. Autores têm autorização para assumir contratos adicionais separadamente, para distribuição não-exclusiva da versão do trabalho publicada nesta revista (ex.: publicar em repositório institucional ou um capítulo de livro).

\section{PUBLISHER}

Universidade Federal de Santa Catarina. Curso de Ciências Contábeis e Programa de Pós-graduação em Contabilidade. Publicação no Portal de Periódicos UFSC. As ideias expressadas neste artigo são de responsabilidade de seus autores, não representando, necessariamente, a opinião dos editores ou da universidade.

\section{EDITORES}

Carlos Eduardo Facin Lavarda e Suliani Rover

\section{HISTÓRICO}

Recebido em: 14/10/2020 - Revisado por pares em: 21/01/2021 - Reformulado em: 14/02/2021 Recomendado para publicação em: 17/02/2021 - Publicado em: 22/03/2021 